\title{
Chapter 4 \\ Adult Cognitive and Non-cognitive Skills: An Overview of Existing PIAAC Data
}

\author{
Débora B. Maehler and Ingo Konradt
}

\begin{abstract}
As of summer 2019, more than 60 PIAAC datasets from participating countries worldwide were available for research purposes. These datasets can be differentiated, for example, in terms of their accessibility, the extent of the information provided, the population group in focus, and the design of the underlying study. PIAAC Public Use Files, for instance, are freely available and are therefore highly anonymised, whereas PIAAC Scientific Use Files are available only for scientific research purposes and provide access to more detailed variables. The majority of the PIAAC data are available as public use files, but some participating countries (e.g. Germany and the United States) have also made several scientific use files or other extended file versions available to the research community. Some of the available PIAAC datasets focus on specific population groups-for example, the incarcerated adult population in the United States. Regarding the design of the underlying studies, most available datasets are cross-sectional, but some longitudinal data already exist (e.g. PIAAC-L in Germany). The present chapter provides an overview of the structure, accessibility, and use of the PIAAC datasets available worldwide.
\end{abstract}

\subsection{Overview of PIAAC Data Available for Secondary Analysis}

Based on the PIAAC data, diverse interdisciplinary questions-such as social inequality, competency and ageing issues, and the role of digitalisation-can be investigated in an internationally comparable way, thereby addressing genuine political demands. PIAAC data contain information about basic skills (literacy, numeracy, and problem solving in technology-rich environments) that are considered to be prerequisites for understanding specific domains of knowledge in a broad

D. B. Maehler $(\varangle) \cdot$ I. Konradt

GESIS - Leibniz Institute for the Social Sciences, Mannheim, Germany

e-mail: debora.maehler@gesis.org

(C) The Author(s) 2020

D. B. Maehler, B. Rammstedt (eds.), Large-Scale Cognitive Assessment,

Methodology of Educational Measurement and Assessment,

https://doi.org/10.1007/978-3-030-47515-4_4 
range of contexts, from education through work to everyday life. Furthermore, the PIAAC data include a wide range of information on variables, such as social background, and engagement with literacy, numeracy, and information and communication technologies (ICTs) that influence the development and maintenance of skills. The data also include information on respondents' current activity, employment status and income, and generic skill use in the workplace (e.g. social skills, manual skills). In addition, PIAAC includes questions on health status, volunteering, political efficacy, and social trust (OECD 2014).

The number of publications that refer to PIAAC has increased strongly in recent years (for an overview, see Maehler et al. 2020). Questions addressed by these publications include, for example:

- To what extent does the educational attainment acquired through formal education predict literacy skills needed in daily life?

- What is the relationship between skills and labour market outcomes in terms of wages and employment chances?

- Who participates in further education, and why?

- How should the (forced) migrant population be covered in future surveys?

- How is test taking (dis)engagement related to cognitive ability or item difficulty?

- To what extent are non-cognitive skills (e.g. the Big Five) related to cognitive skills such as literacy?

The present chapter provides an overview of the PIAAC datasets available worldwide (see Table 4.1). ${ }^{1}$ It differentiates the available datasets in terms of their accessibility, the extent of the information provided, the population group in focus, and the design of the underlying study. For example, PIAAC Public Use Files are accessible mainly for public purposes and are therefore highly anonymised, whereas PIAAC Scientific Use Files and Restricted Use Files provide access to more detailed variables and are available only for scientific research purposes after signing a data use agreement, as they may contain individually identifiable information that is confidential and protected by law. By contrast, public use files are freely available and integrated in data analysis web tools (see Chaps. 5 and 6 in this volume), which take the complex study design into account and allow international comparisons to be made without advanced knowledge of statistical programmes. Scientific use files are provided mainly by the statistics centres or research data centres of the respective countries. For data protection reasons, access to scientific use files is subject to the conclusion of a data use agreement, and sophisticated statistical knowledge is required for their evaluation (see, e.g. Chaps. 7, 8, 9, and 10 in this volume). The present chapter also presents PIAAC datasets that focus on specific population groups-for example, the population of 66- to 80-year-olds in Germany (Friebe

\footnotetext{
${ }^{1}$ In March 2019, we wrote to all current and former PIAAC national project managers inquiring whether PIAAC datasets other than public use files were available to the scientific community. Hence, although we do not claim that the information provided here is exhaustive, we did make every effort to ensure that it is comprehensive.
} 
et al. 2017) and the incarcerated adult population in the United States (Hogan et al. 2016a). Regarding the design of the underlying studies, although some longitudinal data exist, most available datasets are cross-sectional. All datasets reported in this chapter are listed in the reference list.

The most datasets presented in what follows can be merged using the respondent ID in order to perform cross-national analyses. When merging the datasets for the various countries, the variables SEQID and CNTRYID_E should be used as identifiers. Although SEQID is a unique identification key within each country dataset, it is not unique across countries. Thus, an identifier combining both variables must be created. Variable labels are identical throughout all PIAAC Public Use Files. Labels in the PIAAC Scientific Use Files (e.g. the German Scientific Use File) may differ in the case of variables that include country-specific information when categories are collapsed for data protection reasons (e.g. CNT_CITSHIP). Therefore, in order to avoid loss of information, care must be taken when merging datasets. The International Database (IDB) Analyzer can also be used to merge PIAAC datasets (see also Chap. 6 in this volume).

The datasets are presented in this chapter in the order in which they appear in the columns in Table 4.1, beginning with the public use files and ending with the description of the PIAAC datasets on non-cognitive skills. The datasets of the countries within the different dataset groups are presented in alphabetical order.

\subsection{PIAAC Public Use Files}

File Description The PIAAC Public Use Files contain information on the respondents' background and on their cognitive assessment (in literacy, numeracy, and problem solving in technology-rich environments).

Mode of Data Collection Face-to-face interview (computer-assisted personal interview, CAPI) to collect the background information; computer-based or paper-based assessment of skills in literacy, numeracy, and problem solving in technology-rich environments.

Sample Description and Size In each participating country, the sample comprised approximately 5000 adults aged $16-65$ years. $^{2}$

Format and Access The PIAAC Public Use Files (see OECD 2016d to OECD 2016gg; OECD 2019b to OECD 2019g) ${ }^{3}$ containing individual unit record data are freely available and accessible for downloading in SAS, SPSS, and CSV format (https://www.oecd.org/skills/piaac/data/) for each of the countries that participated

\footnotetext{
${ }^{2}$ Some countries have fewer participants, and some countries (e.g. Canada, with 27,285 participants) have an oversample.

${ }^{3}$ Data for Indonesia are not available; however, results for that country are presented in the international report for the second round of PIAAC (OECD 2016a).
} 

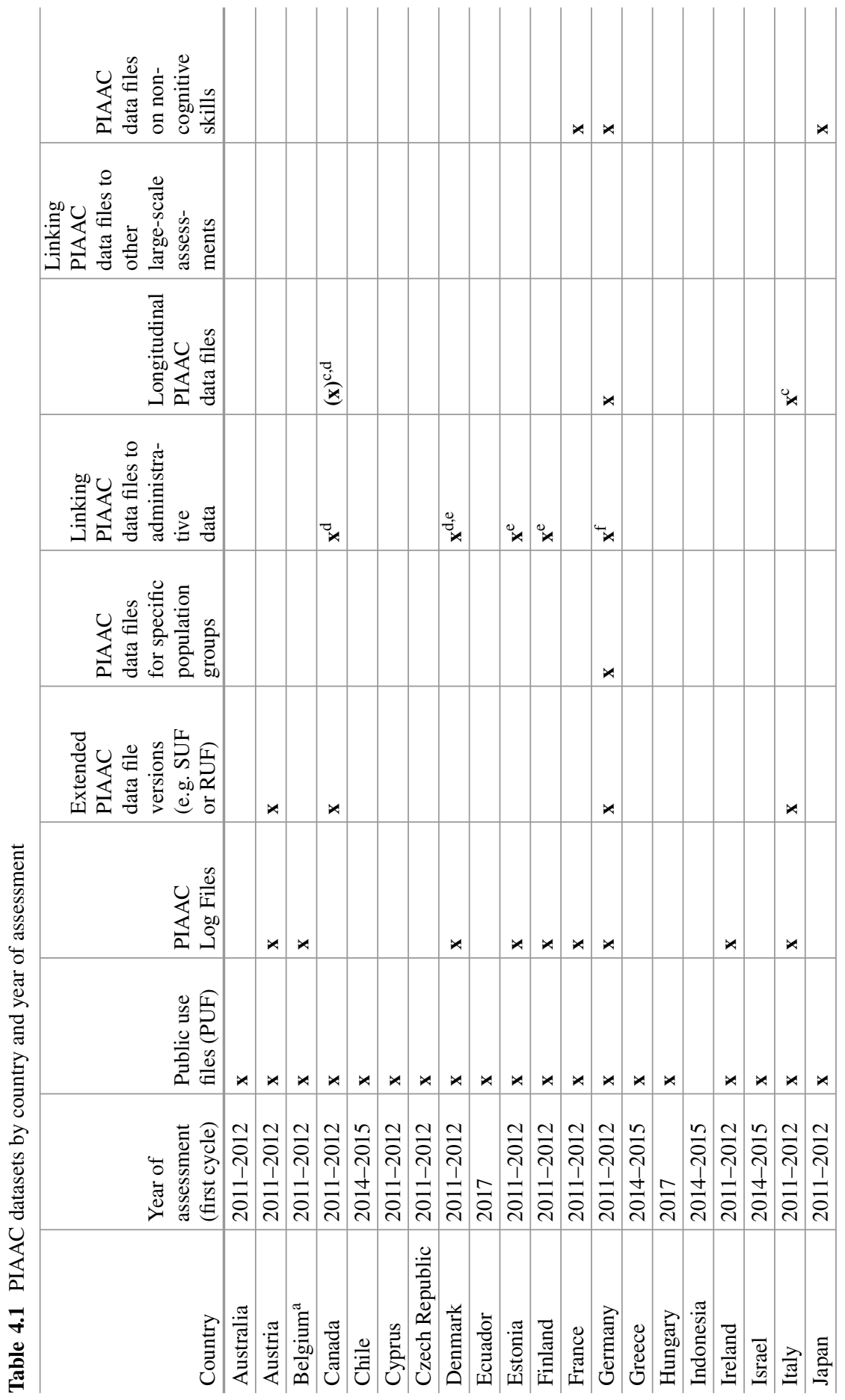


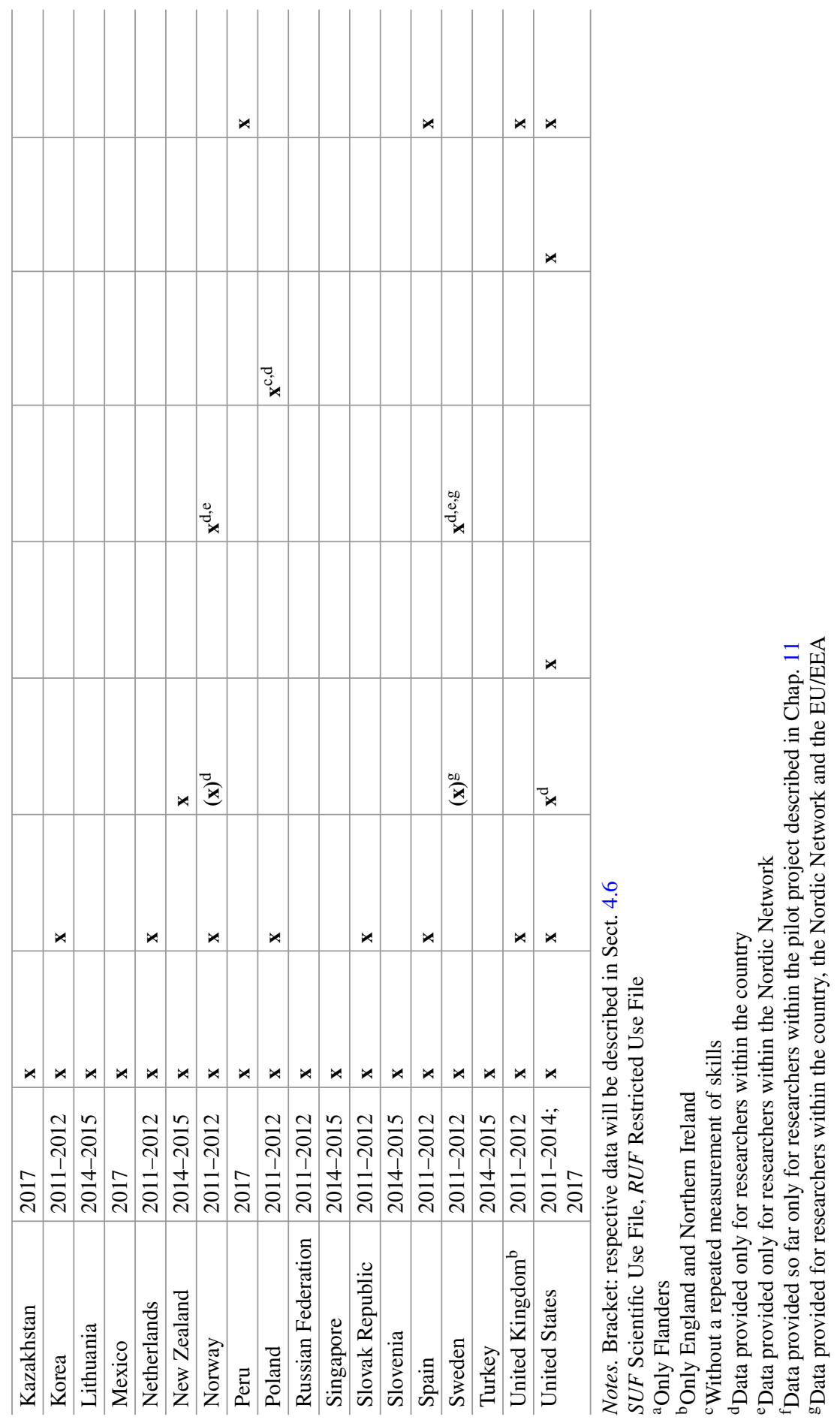


in the Survey of Adult Skills in 2011-2012 (Round 1 of the first cycle: 24 countries), 2014-2015 (Round 2 of the first cycle: nine countries), and 2017 (Round 3 of the first cycle: six countries). A do-file to import CSV into Stata is also available.

The Australian PIAAC Public Use File is not available on the OECD website. However, researchers can apply to the Australian Bureau of Statistics for data access $^{4}, 5$ or use the International Data Explorer to analyse the Australian data (see Chap. 5 in this volume).

The Cypriot PIAAC Public Use File (Michaelidou-Evripidou et al. 2016) is available for downloading in SPSS and Stata format at the GESIS Data Archive. ${ }^{6}$ The US PIAAC Public Use File (Holtzman et al. 2014a) is also downloadable in SPSS, SAS, and ASCII format at the National Center for Education Statistics. ${ }^{7}$ The Canadian PIAAC Public Use File (Canadian Public Use Microdata File/PUMF) ${ }^{8}$ is also provided by Statistics Canada. ${ }^{9}$

For cross-national analyses, the public use files can be merged using the respondent ID. The International Database (IDB) Analyzer can also be used to merge the PIAAC datasets (see Chap. 6 in this volume).

Documentation Information on the methodology, design, and implementation of PIAAC can be found in the technical reports on the study (OECD 2014, 2016a; see also Chap. 2 in this volume) and in the results reports (OECD 2013, 2016b, c). An international master questionnaire is available for downloading at the OECD PIAAC Data and Tools webpage. ${ }^{10}$ The questionnaires in the country-specific languages are also available on that webpage, as are an international codebook and a derived variables codebook.

\subsection{PIAAC Log Files}

File Description The log files from the PIAAC study provide information on how participants processed their answers (OECD 2019a). During the PIAAC assessment 2011-2012 (Round 1 of the first cycle), user interactions with the computer were logged automatically. This means that respondents' actions (e.g. starting a unit, opening a webpage, entering an answer) within the assessment tool were recorded and stored with time stamps in separate log files. These log files contain paradata

\footnotetext{
${ }^{4}$ Current email address: microdata.access[at]abs[dot]gov[dot]au

${ }^{5}$ See also: https://www.abs.gov.au/websitedbs/D3310114.nsf/home/How+to+Apply+for+Micro data

${ }^{6}$ See https://doi.org/10.4232/1.12632

${ }^{7}$ https://nces.ed.gov/pubsearch/pubsinfo.asp?pubid=2014045REV

${ }^{8}$ See also http://www.piaac.ca/597/PUBLIC_USE_FILES.html

${ }^{9}$ Contact: STATCAN.infostats-infostats.STATCAN@ canada.ca

${ }^{10} \mathrm{http}: / /$ www.oecd.org/skills/piaac/data/
} 
for each participant in the domains of literacy, numeracy, and/or problem solving in technology-rich environments. More information on the log files and their analysis is available in Chap. 10 of this volume.

Sample Description and Size PIAAC log file data are available for 17 countries that participated in Round 1 of the PIAAC study (see Table 4.1). The sample in each participating country comprised approximately 5000 adults aged 16-65 years.

Format and Access The log data from the PIAAC cognitive assessments are available as public use files (see OECD 2017a to OECD 2017q) and can be downloaded free of charge from the GESIS Data Archive ${ }^{11}$ after registering on the corresponding webpage. The PIAAC log files are provided in their raw XML format. The files usually contain the complete log data for individual respondents. However, information that could potentially identify an individual respondent has been removed. The data can be matched with corresponding background and cognitive response data available in the PIAAC Public Use Files using the SEQID variable.

To help researchers to analyse log data, a customised analysis tool-the PIAAC LogDataAnalyzer-is available (access currently here: http://piaac-logdata.tbahosting.de/download/). The tool includes functions such as data extraction, data cleaning, and the visualisation of the log data files. The tool can be used for some data analysis tasks as well as for the export of selected data to data files that can be used by other tools. Users can select variables for export. When doing so, predefined variables can be generated, for example: 'Number of using cancel button'; 'Time on task'; and 'Number of page visits'.

Documentation Information on the methodology, design, and implementation of PIAAC can be found in the technical reports on the study (OECD 2014, 2016a; see also Chap. 2 in this volume) and in the results reports (OECD 2013, 2016b, c). An overview of process data recorded in log files in the PIAAC study and how to use them can be found in OECD (2019a), in Chap. 10 of the present volume, and on the PIAAC Log Data Documentation webpage ${ }^{12}$. The aforementioned webpage provides, inter alia, information on released items, an overview of the interactions that are possible with the items, the corresponding log events, and the booklet order of the domains of cognitive assessment.

The documentation regarding released items is available for all users. Depending on the research question, the full documentation with information about nonreleased items may be required. As the full documentation contains information regarding non-released items, individuals who wish to obtain access must apply to the OECD and sign a confidentiality agreement. ${ }^{13}$ The completed application form and the signed confidentiality agreement must be sent to the contact officer at the

\footnotetext{
${ }^{11}$ https://doi.org/10.4232/1.12955

${ }^{12} \mathrm{https}: / /$ piaac-logdata.tba-hosting.de/

${ }^{13}$ https://www.oecd.org/skills/piaac/data/piaaclogfiles
} 
$\mathrm{OECD}^{14}$. If the application is approved, the user will be provided with a username and password that will grant access to the full documentation online.

\subsection{Extended PIAAC Data File Versions}

This section describes extended national datasets that are available for Austria, Canada, Germany, Italy, New Zealand, and the United States. They contain additional information (e.g. some of the national adaptations) and/or more detailed information (e.g. age or income).

Extended data files are also available for Norway (see Norwegian Center for Research Data) ${ }^{15}$ and Sweden (see Statistics Sweden). ${ }^{16}$ However, rules of use in these countries are more restrictive (permitted only for researchers within the country), and information is available only in the language of the respective country. As the Norwegian and Swedish PIAAC data can be linked to administrative information, the datasets will be presented in Sect. 4.6 on the linking of PIAAC data to administrative data.

\subsubsection{Austria}

\subsubsection{Extended PIAAC Public Use File for Austria}

File Description The Austrian PIAAC Public Use File (OECD 2016d) contains information on the respondents' background and on their cognitive assessment (in literacy, numeracy, and problem solving in technology-rich environments). The Extended PIAAC Public Use File for Austria contains additional national education variables.

Mode of Data Collection Face-to-face interview (computer-assisted personal interview, CAPI) to collect the background information; computer-based or paper-based assessment of skills in literacy, numeracy, and problem solving in technology-rich environments.

Sample Description and Size The sample comprised 5130 adults aged 16-65 years.

Format and Access The dataset (Statistics Austria 2015) is available for downloading free of charge (in SPSS and Excel format) at Statistics Austria's website. ${ }^{17}$ The Extended PIAAC Public Use File for Austria can be merged with the PIAAC

\footnotetext{
${ }^{14}$ edu[dot]piaac[at]oecd[dot]org

${ }^{15} \mathrm{https}: / / \mathrm{nsd} . \mathrm{no} / \mathrm{nsd} / \mathrm{english} /$ index.html

${ }^{16} \mathrm{https}: / /$ www.scb.se/en/

${ }^{17}$ http://www.statistik.at/web_en/statistics/
} 
datasets of other participating countries in order to perform cross-national analyses. The International Database (IDB) Analyzer can be used to merge the PIAAC datasets (see Chap. 6 in this volume).

Documentation Information on the methodology, design, and implementation of PIAAC can be found in the technical reports on the study (OECD 2014, 2016a; see also Chap. 2 in the present volume) and in the results reports (OECD 2013, 2016b, c). The international master questionnaire, the international codebook, and a derived variables codebook are available on the OECD PIAAC Data and Tools webpage. A German version of the background questionnaire is available for downloading at Statistics Austria's website. ${ }^{18}$

\subsubsection{Scientific Use File PIAAC 2011/2012 for Austria}

File Description The Austrian PIAAC Public Use File (OECD 2016d) contains information on the respondents' background and on their cognitive assessment (in literacy, numeracy, and problem solving in technology-rich environments). It excludes certain background variables (e.g. some of the national adaptations), and some variables were not released in all the available detail. The majority of the variables were suppressed or coarsened to comply with national data protection legislation. The Austrian PIAAC Scientific Use File includes many of the suppressed background variables. Furthermore, other variables (e.g. age and income) have been released in full detail.

Mode of Data Collection Face-to-face interview (computer-assisted personal interview, CAPI) to collect the background information; computer-based or paper-based assessment of skills in literacy, numeracy, and problem solving in technology-rich environments.

Sample Description and Size The sample comprised 5130 adults aged 16-65 years.

Format and Access The dataset (Statistics Austria 2014) is available in SPSS format and is accessible for academic research only. Researchers must sign an individual data distribution contract (in English or German) provided at Statistics Austria's website $^{19}$. The data distribution contract must be signed by the project leader; key information (e.g. title, description, and duration of project) about the project and the user(s) must be provided. The data are delivered free of charge. Users are expected to make publications resulting from the research available to the data provider. The Scientific Use File PIAAC 2011/2012 for Austria can be merged with the PIAAC datasets of other participating countries in order to perform cross-national analyses.

\footnotetext{
${ }^{18}$ http://www.statistik.at/web_de/statistiken/menschen_und_gesellschaft/bildung/piaac/piaac_ 2011_12_datensaetze_und_fragebogen/index.html

${ }^{19} \mathrm{http} / / /$ www.statistik.at/web_en/statistics/
} 
The International Database (IDB) Analyzer can also be used to merge the PIAAC datasets (see Chap. 6 in this volume).

Documentation Information on the methodology, design, and implementation of PIAAC can be found in the technical reports on the study (OECD 2014, 2016a; see also Chap. 2 in this volume) and in the results reports (OECD 2013, 2016b, c). The international master questionnaire, the international codebook, and a derived variables codebook are available on the OECD PIAAC Data and Tools webpage. A German version of the background questionnaire is available for downloading at Statistics Austria's website. ${ }^{20}$

\subsubsection{Canada}

\subsubsection{Canadian Public Use Microdata File (PUMF)}

File Description While the Canadian PIAAC Public Use File (OECD 2016f) contains information on the respondents' background and on their cognitive assessment (in literacy, numeracy, and problem solving in technology-rich environments), the Canadian PIAAC Public Use Microdata File (PUMF; Statistics Canada 2013) contains additional national variables (e.g. education).

Mode of Data Collection Face-to-face interview (computer-assisted personal interview, CAPI) to collect the background information; computer-based or paper-based assessment of skills in literacy, numeracy, and problem solving in technology-rich environments.

Sample Description and Size The sample comprised 26,683 adults aged 1665 years.

Format and Access The dataset (Statistics Canada 2013) ${ }^{21}$ can be ordered free of charge (in SPSS and Excel format) at Statistics Canada's website. ${ }^{22}$ The PUMF can be merged with the PIAAC datasets of other participating countries in order to perform cross-national analyses. The International Database (IDB) Analyzer can be used to merge the PIAAC datasets (see Chap. 6 in this volume).

Documentation English-language and French-language information on the methodology, design, and implementation of PIAAC can be found on the Canadian PIAAC website (http://www.piaac.ca). Furthermore, general information on the methodology, design, and implementation of PIAAC can be found in the technical

\footnotetext{
${ }^{20} \mathrm{http} / / /$ www.statistik.at/web_de/statistiken/menschen_und_gesellschaft/bildung/piaac/piaac_ 2011_12_datensaetze_und_fragebogen/index.html

${ }^{21}$ See also http://www.piaac.ca/597/PUBLIC_USE_FILES.html.

${ }^{22} \mathrm{https} / / /$ www150.statcan.gc.ca/n1/en/catalogue/89-555-X2013002
} 
reports on the study (OECD 2014, 2016a; see also Chap. 2 in this volume) and in the results reports (OECD 2013, 2016b, c). The PIAAC questionnaires (in English and French) can be downloaded at Statistics Canada's website. ${ }^{23}$ The international master questionnaire, the international codebook, and a derived variables codebook are available on the OECD PIAAC Data and Tools webpage. Furthermore, a Canadian Data Dictionary is available at the Canadian PIAAC website.

\subsubsection{Germany}

\subsubsection{PIAAC Germany Scientific Use File (SUF)}

File Description The German PIAAC Public Use File (OECD 2016h) contains information on the respondents' background and on their cognitive assessment (in literacy, numeracy, and problem solving in technology-rich environments). It suppresses certain background variables (e.g. some of the national adaptations), and some of the included variables have not been released in all available detail. Background variables were suppressed or coarsened to comply with national data protection legislation. The German PIAAC Scientific Use File includes many of these suppressed variables and releases other variables in full detail (e.g. age and income).

Mode of Data Collection Face-to-face interview (computer-assisted personal interview, CAPI) to collect the background information; computer-based or paper-based assessment of skills in literacy, numeracy, and problem solving in technology-rich environments.

Sample Description and Size The sample comprised 5465 adults aged 16-65 years.

Format and Access The dataset (Rammstedt et al. 2016a) is available in SPSS and Stata format for academic research only, after signing a data distribution contract (in English or German). ${ }^{24}$ The data distribution contract requires the provision of key information about the project (e.g. title, description, and duration) and the users. The data can be used only during the time period specified by the contract. Users are charged a processing fee. The PIAAC Germany Scientific Use File can be merged with the PIAAC datasets of other participating countries in order to perform crossnational analyses (the procedure is described by Perry et al. 2017). The International Database (IDB) Analyzer can also be used to merge the PIAAC datasets (see Chap. 6 in this volume).

Documentation Information on the methodology, design, and implementation of PIAAC in Germany can be found in the technical report on the study (Zabal et al.

\footnotetext{
${ }^{23}$ http://www23.statcan.gc.ca/imdb-bmdi/instrument/4406_Q1_V4_B.pdf

${ }^{24} \mathrm{https}: / /$ www.gesis.org/en/piaac/rdc/data/national-scientific-use-files
} 
2014) and in the results reports (OECD 2013; Rammstedt et al. 2013). The German background questionnaire is available in PDF format ${ }^{25}$ and in HTML format. ${ }^{26} \mathrm{~A}$ codebook in Excel format and a study description are available at the GESIS Data Archive. ${ }^{27}$ Further documentation is also available on the PIAAC Research Data Center website. ${ }^{28}$ Moreover, a User Guide (Perry et al. 2017) provides information necessary for conducting basic analyses using the corresponding PIAAC data.

\subsubsection{PIAAC Germany Scientific Use File (SUF): Regional Data}

File Description This dataset provides detailed regional information that was excluded from the regular German PIAAC Scientific Use File due to national data protection legislation. Additionally available indicators include, for example, municipality code, classified size of the political municipality, and number of the sample point.

Mode of Data Collection For the sample selection of the PIAAC study in Germany, the regional information was extracted from the official statistics of the Federal Statistical Office as of December 30, 2009 (Zabal et al. 2014).

Sample Description and Size The sample comprised 5465 adults aged 16-65 years.

Format and Access The dataset (Rammstedt et al. 2016b) is available in SPSS and Stata format and accessible for academic research only. For analyses, the data must be merged with the German PIAAC Scientific Use File (Rammstedt et al. 2016a) using the respondent ID. Use of these regional data is subject to special contractual provisions. Due to the sensitive nature of the data, special restrictions apply, and the data can be analysed only on-site at a guest workstation in the Safe Room at GESIS (contact: PIAAC Research Data Center). ${ }^{29}$

Documentation Information on the methodology, design, and implementation of PIAAC in Germany can be found in the technical report on the study (Zabal et al. 2014) and in the results reports (OECD 2013; Rammstedt et al. 2013). The German background questionnaire is available in PDF format ${ }^{30}$ and in HTML format. ${ }^{31}$ A codebook in Excel format and a study description are available at the GESIS Data

\footnotetext{
${ }^{25} \mathrm{https}: / /$ dbk.gesis.org/dbksearch/download.asp?id=52598

${ }^{26} \mathrm{https} / / /$ www.oecd.org/skills/piaac/data/Translated_HTML_de-DE.htm

${ }^{27}$ https://search.gesis.org/research_data/ZA5845

${ }^{28} \mathrm{https} / / / \mathrm{www}$. gesis.org/en/piaac/rdc/data/national-scientific-use-files

${ }^{29} \mathrm{fdz}$-piaac(at)gesis(dot)org

${ }^{30} \mathrm{https}: / / \mathrm{dbk}$. gesis.org/dbksearch/download.asp?id=52598

${ }^{31} \mathrm{https} / / /$ www.oecd.org/skills/piaac/data/Translated_HTML_de-DE.htm
} 
Archive. ${ }^{32}$ Further documentation is also available on the PIAAC Research Data Center website. ${ }^{33}$

\subsubsection{PIAAC Germany Scientific Use File (SUF): Microm Data}

File Description The dataset contains contextual information that describes either the household or the neighbourhood of the respondents. This information was not included in the regular PIAAC Scientific Use File due to national data protection legislation. These spatial data are provided by microm Micromarketing-Systeme und Consult GmbH in Neuss, Germany. ${ }^{34}$ The microm data available include more than 100 variables from the domains of sociodemographics and socio-economics, consumer behaviour, area and site planning, and strategic segmentation models. For example, variables contain information about the type of residential area, the number of private households and businesses, sociodemographic and socio-economic characteristics (e.g. unemployment, religious denominations, ethnic composition), mobility (e.g. population fluctuation), affinity towards fundraising, communications and print media, Sinus-Milieus ${ }^{\circledR}$, and purchasing power at the level of street sections.

Mode of Data Collection The microm data are compiled from several cooperation partners, with a focus on market research (e.g. public opinion), financial data (e.g. credit institutions), or institutions working with digital or IT data (e.g. telephone companies). The PIAAC survey collects the background information by means of a face-to-face interview (computer-assisted personal interview, CAPI); the assessment of skills in literacy, numeracy, and problem solving in technology-rich environments is computer-based or paper-based.

Sample Description and Size The sample comprised 5465 adults aged 16-65 years.

Format and Access The dataset (Rammstedt et al. 2017a, b) is available in SPSS and Stata format and accessible for academic research only. For analyses, the data must be merged with the German PIAAC Scientific Use File (Rammstedt et al. 2016a) using the respondent ID. Use of this dataset is subject to special contractual provisions. Due to the sensitive nature of the data, special restrictions apply, and the data can be analysed only on-site at a guest workstation in the Safe Room at GESIS (contact: PIAAC Research Data Center). ${ }^{35}$

Documentation Information on the methodology, design, and implementation of PIAAC in Germany can be found in the technical report on the study (Zabal et al. 2014) and in the results reports (OECD 2013; Rammstedt et al. 2013). The German

\footnotetext{
${ }^{32} \mathrm{https} / / /$ search.gesis.org/research_data/ZA5963

${ }^{33} \mathrm{https}: / / \mathrm{www}$.gesis.org/en/piaac/rdc/data/national-scientific-use-files

${ }^{34} \mathrm{https}: / /$ www.microm.de/

${ }^{35} \mathrm{fdz}$-piaac(at)gesis(dot)org
} 
background questionnaire is available in PDF format ${ }^{36}$ and in HTML format. ${ }^{37}$ A codebook in Excel format and a study description are available at the GESIS Data Archive $^{38}$. Further documentation is also available on the PIAAC Research Data Center website. ${ }^{39}$

\subsubsection{Italy}

\subsubsection{PIAAC Italian Extended File}

File Description For Italy, an Extended PIAAC Public Use File contains additional national variables on respondent's background-for example, regional information (macro region: North East, North West, Centre, South, Islands) and information on parents' occupation (e.g. according to ISCO-08).

Mode of Data Collection Face-to-face interview (computer-assisted personal interview, CAPI) to collect the background information; computer-based or paper-based assessment of skills in literacy, numeracy, and problem solving in technology-rich environments.

Sample Description and Size The sample comprised 4621 adults aged 16-65 years.

Format and Access The Italian PIAAC Public Use File - Extended (INAPP 2018) is usually provided in SPSS format. However, on specific request, the dataset can also be provided in SAS or Stata format. Researchers or other interested persons must sign an individual data distribution contract (in English or Italian) provided by the Istituto Nazionale per l'Analisi delle Politiche Pubbliche INAPP ${ }^{40}$. The agreement does not specify a data usage period. The data are provided free of charge. The Italian PIAAC Public Use File - Extended can be merged with the public use files of other participating countries in order to perform cross-national analyses. The International Database (IDB) Analyzer can be used to merge the PIAAC datasets (see Chap. 6 in this volume).

Documentation Information on the methodology, design, and implementation of PIAAC can be found in the technical reports on the study (OECD 2014, 2016a; see also Chap. 2 in this volume) and in the results reports (OECD 2013, 2016b, c). An Italian-language version of the background questionnaire is available for downloading at the INAPP website ${ }^{41}$. The questionnaire is also available on the

\footnotetext{
${ }^{36}$ https://dbk.gesis.org/dbksearch/download.asp? $\mathrm{id}=52598$

${ }^{37}$ https://www.oecd.org/skills/piaac/data/Translated_HTML_de-DE.htm

${ }^{38}$ https://search.gesis.org/research_data/ZA5963

${ }^{39} \mathrm{https} / / / \mathrm{www}$.gesis.org/en/piaac/rdc/data/national-scientific-use-files

${ }^{40}$ Current email address: serviziost(at)istico(dot)inapp(dot)org

${ }^{41}$ https://inapp.org/it/dati/piaac
} 
OECD PIAAC Data and Tools webpage, as are an international codebook and a derived variables codebook.

\subsubsection{New Zealand}

\subsubsection{PIAAC New Zealand Extended File}

File Description The New Zealand PIAAC Public Use File (OECD 2016w) contains information on respondents' background and on their cognitive assessment (in literacy, numeracy, and problem solving in technology-rich environments). For New Zealand, an extended public use file is available with country-specific variables (e.g. education) and international variables (e.g. a continuous age variable) that were confidentialised or suppressed for the public use file version.

Mode of Data Collection Face-to-face interview (computer-assisted personal interview, CAPI) to collect the background information; computer-based or paper-based assessment of skills in literacy, numeracy, and problem solving in technology-rich environments.

Sample Description and Size The sample comprised 6177 adults aged 16-65 years. The sample design included screening for two subpopulations, 16- to 25-year-olds and persons of Māori ethnicity. This supports more in-depth analysis by providing additional samples for these subpopulations. The total achieved sample sizes for the subpopulations were 16- to 25-year-olds, $N=1422$, and Māori, $N=1146$.

Format and Access The extended New Zealand PIAAC Public Use File (Ministry of Education of New Zealand 2016) is provided in a range of formats (SPSS, Stata, and SAS) by the Government of New Zealand. The Ministry of Education makes this dataset available to researchers under a memorandum of understanding (MOU). The following webpage provides information on New Zealand's participation in PIAAC: https:/www.educationcounts.govt.nz/data-services/datacollections/international/piaac. ${ }^{42} \mathrm{~A}$ data usage period is not specified by the contract. The MOU continues to apply while the researcher is using or retains the dataset. The data are provided free of charge.

The PIAAC New Zealand Extended File can be merged with the public or extended use files of other participating countries in order to perform cross-national analyses. The International Database (IDB) Analyzer can be used to merge the PIAAC datasets (see Chap. 6 in this volume).

Documentation Information on the methodology, design, and implementation of PIAAC can be found in the technical reports on the study (OECD 2014, 2016a;

\footnotetext{
${ }^{42}$ The email address for enquiries about this is currently: tertiary[dot]information[at]education[dot]govt[dot]nz.
} 
see also Chap. 2 in this volume) and in the results reports (OECD 2013, 2016b, c). The international master questionnaire, the international codebook, and a derived variables codebook are available on the OECD PIAAC Data and Tools webpage. Furthermore, a data dictionary is available for the New Zealand national variables.

\subsubsection{United States}

\subsubsection{US PIAAC 2012 Restricted Use File (RUF)}

File Description The US PIAAC Restricted Use File (RUF) contains information on respondents' background and on their cognitive assessment (in literacy, numeracy, and problem solving in technology-rich environments) from the US PIAAC main study, for which data collection was completed in 2012. In addition to the variables in the US PIAAC Public Use File (NCES 2014-045REV; OECD 2016gg), the US PIAAC Restricted Use File contains detailed versions of variables (e.g. continuous age and earnings variables) and additional data (e.g. on race and ethnicity) collected through US-specific questionnaire routing. The data contain sensitive information, which is confidential and protected by US federal law.

Mode of Data Collection Face-to-face interview (computer-assisted personal interview, CAPI) to collect the background information; computer-based or paper-based assessment of skills in literacy, numeracy, and problem solving in technology-rich environments.

Sample Description and Size The sample comprised 5010 adults aged 16-65 years.

Format and Access The US PIAAC Restricted Use File (Holtzman et al. 2014b) is available in SPSS and SAS formats and accessible only for scientific research purposes and only in the United States. Individual researchers must apply through an organisation in the United States (e.g. a university or a research institution). The organisation must apply for and sign a contract prior to obtaining access to the restricted-use data. Depending on the type of organisation, this contract takes the form of a restricted-use data licence or a memorandum of understanding (MOU). ${ }^{43}$ The application must be submitted via an online application system ${ }^{44}$. Key information must be provided about the project (e.g. title, description, and duration) and the user. The data can be used only during the time period specified by the contract. Users are charged a processing fee and are expected to make publications resulting from the research available to the data provider.

Documentation Information on the methodology, design, and implementation of PIAAC can be found in the technical reports on the study (OECD 2014, 2016a;

\footnotetext{
${ }^{43}$ For details see https://nces.ed.gov/statprog/instruct_gettingstarted.asp

${ }^{44}$ Currently available at https://nces.ed.gov/statprog/instruct.asp
} 
see also Chap. 2 in this volume) and in the results reports (OECD 2013, 2016b, c). In addition, specific information on the methodology, design, and implementation of PIAAC in the United States can be found in the technical report on the study (Hogan et al. 2013) and in the results reports (Goodman et al. 2013; OECD 2013). An English-language and a Spanish-language background questionnaire (HTML format) are available for downloading at the National Center for Education Statistics website. ${ }^{45}$ The US codebook and background compendium are provided together with the data.

\subsubsection{PIAAC 2012/202014: US National Supplement Public Use Data File (PUF) - Household}

File Description The PIAAC 2012/2014 US National Supplement Public Use Data Files - Household (Holtzman et al. 2016a; NCES 2016667REV) contain information on respondents' background and on their cognitive assessment (in literacy, numeracy, and problem solving in technology-rich environments) from the first and second US PIAAC data collections completed in 2012 and 2014, respectively. The 2014 sampling design supported oversampling (younger adults, aged 16-35, and unemployed adults) and the addition of a population group (older adults, aged 66-74), but the data cannot be analysed separately from the 2012 data on a national level. The expanded national sample of the combined data collections supports more accurate and reliable national estimates for these subgroups and, in the case of older adults, estimates for new groups not represented in the first round of PIAAC.

Mode of Data Collection Face-to-face interview (computer-assisted personal interview, CAPI) to collect the background information; computer-based or paper-based assessment of skills in literacy, numeracy, and problem solving in technology-rich environments.

Sample Description and Size The US PIAAC main study (2012) sample comprised 5010 adults aged 16-65 years. The US PIAAC National Supplement (2014) household sample comprised 3660 adults aged 16-74 years. Hence, the dataset contains a total of 8670 surveyed respondents.

Format and Access The US PIAAC 2012/2014 National Supplement Public Use File (Holtzman et al. 2016a) is available for downloading in SPSS, SAS, and raw format at the National Center for Education Statistics website. ${ }^{46}$ A version of the Public Use File is provided on the OECD website ${ }^{47}$, thus enabling researchers

\footnotetext{
${ }^{45}$ https://nces.ed.gov/surveys/piaac/

${ }^{46} \mathrm{https}: / /$ nces.ed.gov/pubsearch/pubsinfo.asp?pubid=2016667REV

${ }^{47}$ http://www.oecd.org/skills/piaac/publicdataandanalysis/
} 
to conduct cross-country analyses using the 2012/2014 combined household US sample.

Documentation Information on the methodology, design, and implementation of PIAAC can be found in the technical reports on the study (OECD 2014, 2016a; see also Chap. 2 in this volume) and in the results reports (OECD 2013, 2016b, c). In addition, specific information on the methodology, design, and implementation of PIAAC in the United States can be found in the technical report on the study (Hogan et al. 2016a) and in the results report (Rampey et al. 2016). An English-language and a Spanish-language background questionnaire (HTML format) and a codebook and background compendium are available for downloading at the National Center for Education Statistics website. ${ }^{48}$

\subsubsection{PIAAC 2012/2014: US National Supplement Restricted Use Data File (RUF) - Household}

File Description The US PIAAC 2012/2014 National Supplement Restricted Use Data Files - Household (Holtzman et al. 2016b; NCES 2016668REV) contain information on respondents' background and on their cognitive assessment (in literacy, numeracy, and problem solving in technology-rich environments) from the first and second US PIAAC data collections, completed in 2012 and 2014, respectively. The 2014 sampling design supported oversampling (younger adults, aged 16-35, and unemployed adults) and the addition of a population group (older adults, aged 66-74), but the data cannot be analysed separately from the 2012 data on a national level. The expanded national sample of the combined data collections supports more accurate and reliable national estimates for these subgroups and, in the case of older adults, estimates for new groups not represented in the first round of PIAAC. The Restricted Use Files contain detailed versions of variables and additional data collected through US-specific questionnaire routing (e.g. continuous age and earnings variables, language spoken). A detailed variable-level comparison of the PUF and RUF versions is available in the technical report (Table E-5; Hogan et al. 2016).

Mode of Data Collection Face-to-face interview (computer-assisted personal interview, CAPI) to collect the background information; computer-based or paper-based assessment of skills in literacy, numeracy, and problem solving in technology-rich environments.

Sample Description and Size The US PIAAC main study (2012) sample comprised 5010 adults aged 16-65 years. The US PIAAC National Supplement (2014) household sample comprised 3660 adults aged 16-74 years. Hence, the dataset contains a total of 8670 surveyed respondents.

\footnotetext{
${ }^{48} \mathrm{https}: / /$ nces.ed.gov/surveys/piaac/
} 
Format and Access The PIAAC 2012/2014 US National Supplement Restricted Use File (Holtzman et al. 2016b) is available in SPSS and SAS format and accessible only for scientific research purposes and only in the United States. Individual researchers must apply through an organisation in the United States (e.g. a university or a research institution). The organisation must apply for and sign a contract prior to obtaining access to the restricted-use data. Depending on the type of organisation, this contract takes the form of a restricted-use data licence or a memorandum of understanding (MOU). The application must be submitted via an online application system $^{49}$. Key information must be provided about the project (e.g. title, description, and duration) and the user. The data can be used only during the time period specified by the contract. Users are charged a processing fee and are expected to make publications resulting from the research available to the data provider.

A synthetic version of the Restricted Use File (S-RUF) is provided on the OECD website ${ }^{50}$ in order to enable researchers outside the United States to prepare computer code for the analysis of PIAAC data on the US Restricted Use File (RUF). The generated code (in SAS, SPSS, or Stata) must then be submitted to the American Institutes for Research ${ }^{51}$, where the requested analyses will be run on the real US RUF. The output undergoes a confidentiality review and is returned to the researcher after approval. The synthetic version does not include variables with open-ended/verbatim responses or variables with a high degree of detail (e.g. occupation).

Documentation Information on the methodology, design, and implementation of PIAAC can be found in the technical reports on the study (OECD 2014, 2016a; see also Chap. 2 in this volume) and in the results reports (OECD 2013, 2016b, c). In addition, specific information on the methodology, design, and implementation of PIAAC in the United States can be found in the technical report on the study (Hogan et al. 2016a) and in the results report (Rampey et al. 2016). An Englishlanguage and a Spanish-language background questionnaire (HTML format) are available for downloading at the National Center for Education Statistics website. ${ }^{52}$ The codebook and background compendium are provided together with the data. For the synthetic version of the RUF (and researchers outside the United States), a codebook and a User Guide are available on the OECD PIAAC Data and Tools webpage.

\footnotetext{
${ }^{49}$ Currently available at https://nces.ed.gov/statprog/instruct.asp

${ }^{50} \mathrm{http} / / /$ www.oecd.org/skills/piaac/publicdataandanalysis/

${ }^{51}$ piaac[at]air[dot]org

${ }^{52} \mathrm{https}: / /$ nces.ed.gov/surveys/piaac/
} 


\subsection{PIAAC Data Files with a Focus on Specific Population Groups}

\subsubsection{Germany}

\subsubsection{German PIAAC National Supplement (SUF): Prime Age}

File Description The German PIAAC Prime Age dataset comprises a national oversample of adults in former East Germany aged 26-55 years from Round 1 of the PIAAC data collection in Germany, which was completed in 2012. This is considered to be an age group whose members are in the active employment phase and have usually completed vocational training. Respondents were surveyed using the same procedures, instruments, and assessments that were used for the PIAAC main study. The dataset contains background information and information on the cognitive assessment (in literacy, numeracy, and problem solving in technology-rich environments).

Mode of Data Collection Face-to-face interview (computer-assisted personal interview, CAPI) to collect the background information; computer-based or paper-based assessment of skills in literacy, numeracy, and problem solving in technology-rich environments.

Sample Description and Size The oversample comprised 560 adults aged 2655 years. In total (i.e. together with the participants of the German PIAAC main study in the corresponding age group), the sample contains 4000 adults aged 2655 years.

Format and Access The dataset (Solga and Heisig 2015) is available in SPSS and Stata format for academic research only, after signing a data distribution contract (in English or German). ${ }^{53}$ In addition, key information about the project (e.g. title, description, and duration) and the user must be provided. The data can be used only during the time period specified by the contract. Users are charged a processing fee and are expected to make publications resulting from the research available to the data provider.

Documentation Information on the methodology, design, and implementation of PIAAC in Germany can be found in the technical report on the study (Zabal et al. 2014) and in the results reports (OECD 2013; Rammstedt et al. 2013). The German background questionnaire is available in PDF format ${ }^{54}$ and in HTML format. ${ }^{55}$ The

\footnotetext{
${ }^{53}$ Available at https://www.gesis.org/en/piaac/rdc/data/german-piaac-national-supplement

${ }^{54} \mathrm{https}: / /$ dbk.gesis.org/dbksearch/download.asp?id=56322

${ }^{55} \mathrm{https} / / /$ www.oecd.org/skills/piaac/data/Translated_HTML_de-DE.htm
} 
codebook (in Excel format) is available at the GESIS Data Archive ${ }^{56}$, and further documentation is also available on the PIAAC Research Data Center website. ${ }^{57}$.

\subsubsection{German PIAAC National Supplement (SUF): Competencies in Later Life (CiLL)}

File Description The German PIAAC CiLL study (Friebe et al. 2014) comprises a national oversample of adults aged 66-80 years from Round 1 of the PIAAC data collection in Germany, which was completed in 2012. Respondents were surveyed using the same procedures, instruments, and assessments that were used for the PIAAC main study. The dataset contains background information and information on the cognitive assessment (in literacy, numeracy, and problem solving in technology-rich environments).

Mode of Data Collection Face-to-face interview (computer-assisted personal interview, CAPI) to collect the background information; computer-based or paper-based assessment of skills in literacy, numeracy, and problem solving in technology-rich environments.

Sample Description and Size The sample comprised 1392 adults aged 66-80 years.

Format and Access The dataset (Friebe et al. 2017) is available in SPSS and Stata format for academic research only, after signing a data distribution contract (in English or German). ${ }^{58}$ In addition, key information about the project (e.g. title, description, and duration) and the user must be provided. The data can be used only during the time period specified by the contract. Users are charged a processing fee and are expected to make publications resulting from the research available to the data provider.

Documentation Information on the methodology, design, and implementation of PIAAC in Germany can be found in the technical report on the study (Zabal et al. 2014) and in the results reports (OECD 2013; Rammstedt et al. 2013). The German background questionnaire is available in PDF format ${ }^{59}$ and in HTML format. ${ }^{60}$ The codebook in Excel format and a study description are available at the GESIS Data Archive $^{61}$. Further documentation is also available on the PIAAC Research Data Center website. ${ }^{62}$.

\footnotetext{
${ }^{56} \mathrm{https} / / /$ search.gesis.org/research_data/ZA5951

${ }^{57} \mathrm{https}: / /$ www.gesis.org/en/piaac/rdc/data/german-piaac-national-supplement

${ }^{58}$ Available at https://www.gesis.org/en/piaac/rdc/data/german-piaac-national-supplement

${ }^{59} \mathrm{https}: / /$ dbk.gesis.org/dbksearch/download.asp?id=58939

${ }^{60} \mathrm{https} / / /$ www.oecd.org/skills/piaac/data/Translated_HTML_de-DE.htm

${ }^{61} \mathrm{https}: / /$ search.gesis.org/research_data/ZA5969

${ }^{62} \mathrm{https} / / /$ www.gesis.org/en/piaac/rdc/data/german-piaac-national-supplement
} 


\subsubsection{United States}

\subsubsection{PIAAC 2014: US National Supplement Public Use Data Files (PUF)-Prison}

File Description The PIAAC 2014 US National Supplement Public Use Data Files-Prison (Hogan et al. 2016a; NCES 2016337REV) contain information on the background and the cognitive assessment (in literacy, numeracy, and problem solving in technology-rich environments) of incarcerated adults surveyed in the US PIAAC National Supplement Prison Study, data collection for which was conducted in 2014. The direct assessments of literacy, numeracy, and problem solving in technology-rich environments administered to adult inmates were the same as those administered to the US PIAAC household participants. However, the household background questionnaire was modified and tailored specifically to address the experiences and needs of this subgroup.

Mode of Data Collection Face-to-face interview (computer-assisted personal interview, CAPI) to collect the background information; computer-based or paper-based assessment of skills in literacy, numeracy, and problem solving in technology-rich environments.

Sample Description and Size The sample comprised 1319 adults aged 16-74 years incarcerated in prisons in the United States.

Format and Access The PIAAC 2014 US National Supplement Public Use Data Files-Prison (Hogan et al. 2016a) are available for downloading in SPSS, SAS, and raw format at the National Center for Education Statistics website ${ }^{63}$.

Documentation Information on the methodology, design, and implementation of US PIAAC can be found in the technical report on the study (Hogan et al. 2016a) and in the results report (Rampey et al. 2016). An English-language and a Spanish-language background questionnaire (HTML format) and a codebook and background compendium are available for downloading at the National Center for Education Statistics website ${ }^{64}$.

\subsubsection{PIAAC 2014: US National Supplement Restricted Use Data Files (RUF)-Prison}

File Description The PIAAC 2014 US National Supplement Restricted Use Data Files-Prison (Hogan et al. 2016b; NCES 2016058REV) contain information on the background and the cognitive assessment (in literacy, numeracy, and problem solving in technology-rich environments) of incarcerated adults who were surveyed

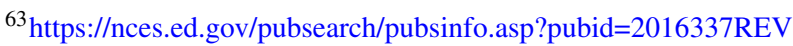

${ }^{64} \mathrm{https}: / /$ nces.ed.gov/surveys/piaac/
} 
in the US PIAAC National Supplement Prison Study, data collection for which was conducted in 2014. The direct assessments of literacy, numeracy, and problem solving in technology-rich environments administered to adult inmates were the same as those administered to the US PIAAC household participants. However, the household background questionnaire was modified and tailored specifically to address the experiences and needs of this subgroup. The Restricted Use File contains detailed versions of variables and additional data collected through US-specific questionnaire routing (e.g. continuous age and earnings variables, language spoken). A detailed variable-level comparison of the PUF and RUF version is available in the technical report (Table E-6; Hogan et al. 2016b).

Mode of Data Collection Face-to-face interview (computer-assisted personal interview, CAPI); computer-based or paper-based measurement of basic skills in literacy, numeracy, and problem solving in technology-rich environments.

Sample Description and Size The sample comprised 1319 adults aged 16-74 years incarcerated in prisons in the United States.

Format and Access The PIAAC 2014 US National Supplement Restricted Use Files-Prison (Hogan et al. 2016b) are available in SPSS and SAS format and accessible only for academic research and only in the United States. Individual researchers must apply for access through an organisation in the United States (e.g. a university or a research institution). The organisation must apply for and sign a contract prior to obtaining access to the restricted-use data. Depending on the type of organisation, this contract takes the form of a restricted-use data licence or a memorandum of understanding (MOU) ${ }^{65}$ The application must be submitted via an online application system ${ }^{66}$. Key information must be provided about the project (e.g. title, description, and duration) and the user. The data can be used only during the time period specified by the contract. Users are charged a processing fee and are expected to make publications resulting from the research available to the data provider.

Documentation Information on the methodology, design, and implementation of US PIAAC can be found in the technical report on the study (Hogan et al. 2016a) and in the results report (Rampey et al. 2016). An English-language and a Spanishlanguage background questionnaire (HTML format) are available for downloading at the National Center for Education Statistics website ${ }^{67}$. The codebook and background compendium are provided together with the data.

\footnotetext{
${ }^{65}$ For details see https://nces.ed.gov/statprog/instruct_gettingstarted.asp

${ }^{66}$ Currently available at https://nces.ed.gov/statprog/instruct.asp

${ }^{67} \mathrm{https}: / /$ nces.ed.gov/surveys/piaac/
} 


\subsection{Linking PIAAC Data Files to Administrative Data}

To date, datasets linking PIAAC data to administrative data are in the pilot phase and are partially available in Canada (Longitudinal and International Study of Adults, LISA), the Nordic countries (Denmark, Estonia, Finland, Norway, and Sweden), and Germany.

In Canada, the LISA data, which include the PIAAC data in the first wave of measurement, are available for in-country research. The LISA data can be linked to historical administrative data since 1982 (e.g. Pension Plan in Canada, PPIC, or the Immigration Database). The linkage to administrative data is available for 8600 LISA respondents who underwent PIAAC assessments (at Wave 1).

Norway and Sweden already offer researchers the possibility of analysing the respective country data on PIAAC by linking them to administrative data. In Norway, however, this possibility is available only to researchers within the country. Therefore, NordMAN (Nordic Microdata Access Network; http://nordman. network/) has been established; it will integrate PIAAC survey data linked to administrative data for five European countries (Denmark, Estonia, Finland, Norway and Sweden) on a common platform, thereby extending the user radius for researchers within the Network. An extension of the use for researchers outside this network is currently being discussed; it is bound up, for example, with legal issues. These data will be described in Sect. 4.6.4.

By means of a pilot project, the German PIAAC-Longitudinal (PIAAC-L) data have been individually linked to the employment biography data provided by the German Institute for Employment Research (IAB). The resulting dataset is known as PIAAC-L-ADIAB. The linked administrative data are available for 2086 PIAAC$L$ respondents (at Wave 1). The data was tested and analysed by researchers in a pilot project. An exemplary description of the work with these data can be found in Chap. 11 in this volume.

\subsubsection{Canada}

\subsubsection{Longitudinal and International Study of Adults (LISA)}

File Description The Longitudinal and International Study of Adults (LISA) examines changes in Canadian society over time. There have been four waves of LISA data collection to date: Wave 1 in 2012, Wave 2 in 2014, Wave 3 in 2016, and Wave 4 in 2018 (not yet released). Data collection for Wave 5 will begin in January 2020. In Wave 1 (2011-2012), to improve operational efficiency and enhance analytical value, LISA and PIAAC shared a portion of their samples. LISA collects a wide range of information about education, training and learning, families, housing, health, labour, income, pensions, spending, and wealth. Variables are obtained through the administration of the survey component and subsequent 
integration with various administrative files. The Canadian PIAAC data contain information on respondents' background and on their cognitive assessment (in literacy, numeracy, and problem solving in technology-rich environments). The target populations of LISA and PIAAC (2011-2012) differed. The LISA target population covered individuals aged 15 years and over, whereas the PIAAC target population covered only 16- to 65-year-olds. The common sample for both PIAAC and LISA allows the analysis of various variables and administrative data with which proficiency scores can be analysed.

Mode of Data Collection Face-to-face interview (computer-assisted personal interview, CAPI) to collect the background information; computer-based or paper-based assessment of skills in literacy, numeracy, and problem solving in technology-rich environments.

Sample Description and Size LISA uses household interviews to collect information from approximately 34,000 Canadians aged 15 years and over from more than 11,000 households (23,900 responding persons in 2012). Data from the PIAAC assessment are available for 8600 respondents and are available only in the LISA 2012 (Wave 1) microdata files.

Format and Access It should be noted that the LISA data are currently available only in Canada, via Canadian Research Data Centres (RDCs). Researchers must submit proposals to the RDC Program requesting LISA data and must specify whether they require access to the LISA survey data or the LISA data integrated with administrative data. The application process and guidelines depend on the affiliation of the principal investigator (e.g. researcher who works for an academic institution that is or is not a member of the Canadian Research Data Centre Network) and the type of research to be conducted. Detailed information on the data access process can be found on the Statistics Canada website ${ }^{68}$ Users are expected to make publications resulting from the research available to the data provider.

Documentation English-language and French-language information on the methodology, design, and implementation of LISA and PIAAC can be found on the Statistics Canada website ${ }^{69}$ and on the Canadian PIAAC website ${ }^{70}$. Furthermore, general information on the methodology, design, and implementation of PIAAC can be found in the technical reports on the study (OECD 2014, 2016a; see also Chap. 2 in this volume) and in the results reports (OECD 2013, 2016b, c). The questionnaires (in English and French) of all waves of LISA can be downloaded at Statistics Canada's website. ${ }^{71}$ The international master questionnaire, the international

\footnotetext{
${ }^{68}$ Current application site: https://www.statcan.gc.ca/eng/rdc/process

${ }^{69} \mathrm{http} / / / \mathrm{www} 23$. statcan.gc.ca/imdb/p2SV.pl?Function=getSurvey $\& \mathrm{Id}=248501$

${ }^{70} \mathrm{http}: / / \mathrm{www}$.piaac.ca

${ }^{71} \mathrm{http}: / /$ www23.statcan.gc.ca/imdb/p3Instr.pl?Function=getInstrumentList\&Item_Id=424373\& $\mathrm{UL}=\mathrm{AV}$
} 
codebook, and a derived variables codebook are available on the OECD PIAAC Data and Tools webpage.

\subsubsection{Norway}

\subsubsection{Linking PIAAC Norway Data to Administrative Data}

File Description The Norwegian PIAAC data contain information on respondents' background and on their cognitive assessment (in literacy, numeracy, and problem solving in technology-rich environments). The PIAAC data provided by the Norwegian Centre for Research Data (NSD) ${ }^{72}$ contain more detailed information-for example, on earnings, country of birth, and occupation (detailed, four-digit, ISCO08 codes) - than that available in the Norwegian PIAAC Public Use File (OECD 2016v).

Furthermore, the Norwegian PIAAC data can be extended with administrative (register) data, such as demographic data (e.g. citizenship and marital status), data on educational attainment and current education, employment, occupation and industry, and information about the workplace of the respondents and about social security for the years 2010-2020. These linked data are provided by Statistics Norway.

Mode of Data Collection PIAAC data: face-to-face interview (computer-assisted personal interview, CAPI) to collect the background information; computer-based or paper-based assessment of skills in literacy, numeracy, and problem solving in technology-rich environments. The administrative data are derived from administrative registers (e.g. the population register).

Sample Description and Size The sample comprised 5128 adults aged 16-65 years.

Format and Access The Norwegian PIAAC data (Statistics Norway 2015) are provided in SPSS, Stata, and SAS format by the Norwegian Centre for Research Data (NSD) to researchers, teachers, and students located in Norway. Data can be ordered via NSD's order form (currently at https://nsd.no/nsd/english/orderform. html). ${ }^{73}$ Users must sign an access letter and a confidentiality agreement that stipulates conditions for use. The data distribution contract must be signed by each member of a project who wishes to use the data. In addition, key information about the project and the user must be provided. The data contract can be concluded for a term of 2 years.

The Norwegian PIAAC dataset can also be extended with variables from administrative registers. Anonymous datasets are created by Statistics Norway for

\footnotetext{
${ }^{72}$ In Norway, PIAAC data are available via NSD, Statistics Norway, and the Nordic PIAAC database (see Sect. 4.6.3 in this volume).

${ }^{73}$ Or: bestilledata[at]nsd[dot]uib[dot]no
} 
specific research projects. In other words, when researchers apply for access, a dataset with the specific variables ordered is created for the research project in question. $^{74}$

Documentation Information on the methodology, design, and implementation of PIAAC can be found in the technical reports on the study (OECD 2014, 2016a; see also Chap. 2 in this volume) and in the results reports (Fridberg et al. 2015; OECD 2013, 2016b, c). There is also a national documentation report (Gravem and Lagerstrøm 2013). Further documentation for administrative data is made available when the data/variables are ordered. A Norwegian-language version of the background questionnaire is available for downloading at the OECD PIAAC Data and Tools webpage, as are an international codebook and a derived variables codebook.

\subsubsection{Sweden}

\subsubsection{Linking PIAAC Sweden Data to Administrative Data}

File Description The Swedish PIAAC data contain information on respondents' background and on their cognitive assessment (in literacy, numeracy, and problem solving in technology-rich environments). The PIAAC data at Statistics Sweden contain more detailed information-for example, on earnings, country of birth, and occupation (detailed, four-digit, ISCO-08) — than that available in the Swedish PIAAC Public Use File (OECD 2016dd). Furthermore, the Swedish PIAAC data were extended with administrative (register) data, such as demographic data (e.g. citizenship and marital status), data on educational attainment and current education, employment, occupation and industry, and information about the workplace of the respondents and about social security. This information is available for the years 2008 and 2011 for each respondent of PIAAC 2012. It is also possible to combine the PIAAC data with register data about the region in which the respondent lives (e.g. NUTS 2).

Mode of Data Collection PIAAC data: face-to-face interview (computer-assisted personal interview, CAPI) to collect the background information; computer-based or paper-based assessment of skills in literacy, numeracy, and problem solving in technology-rich environments. The administrative data are derived from administrative registers (e.g. the population register).

Sample Description and Size The sample comprised 4469 adults aged 16-65 years.

\footnotetext{
${ }^{74}$ More information on access to microdata from Statistics Norway can be found here: https:// www.ssb.no/en/omssb/tjenester-og-verktoy/data-til-forskning.
} 
Format and Access The Swedish PIAAC data are provided in SPSS, Stata, SAS, and $\mathrm{R}$ format for research purposes within the EU/EEA through the remote access system MONA (Microdata Online Access) at Statistics Sweden ${ }^{75}$. MONA is a tool for delivering microdata at Statistics Sweden. Users of MONA work in a Windows environment via remote connection. Microdata are visible on the computer screen and can be processed using statistical software available in MONA. Results can be retrieved via email, but processed microdata are stored in MONA and may not be downloaded.

There is not one standard dataset. Rather, datasets with register variables have to be created for a specific research project. When researchers apply for access, a dataset with the specific variables ordered is created for the research project in question. Research projects must apply to Statistics Sweden for access to the data; a research plan, also containing a description of variables, should be included in the application. Statistics Sweden conducts a confidentiality review based on the research plan. If the application is approved and confidentiality agreements between Statistics Sweden and the research project are signed, the project obtains access to the data through MONA.

Documentation Information on the methodology, design, and implementation of PIAAC can be found in the technical reports on the study (OECD 2014, 2016a; see also Chap. 2 in this volume) and in the results reports (Fridberg et al. 2015; OECD 2013, 2016b, c). Further documentation for administrative data is made available when the data/variables are ordered. A Swedish-language version of the background questionnaire is available for downloading at the OECD PIAAC Data and Tools webpage, as are an international codebook and a derived variables codebook.

\subsubsection{The Nordic PIAAC Database}

File Description The Nordic PIAAC database contains microdata from the survey, as well as data from registers of five Nordic European countries: Denmark, Estonia, Finland, Norway, and Sweden. It contains information on respondents' background and on their cognitive assessment (in literacy, numeracy, and problem solving in technology-rich environments) from the PIAAC data collection completed in 2012. Furthermore, data from national registers in Denmark, Estonia, Finland, and Sweden for the reference years 2008 and 2011 and in Norway for 2011 are available for each respondent. Diverse types of register data are available, such as demographic data (e.g. citizenship and marital status), data on educational attainment and current education, employment, occupation and industry, and information about the workplace of the respondents and about social security.

\footnotetext{
${ }^{75} \mathrm{https}: / / w w w . s c b . s e / e n /$.
} 
Mode of Data Collection PIAAC data: face-to-face interview (computer-assisted personal interview, CAPI) to collect the background information; computer-based or paper-based assessment of skills in literacy, numeracy, and problem solving in technology-rich environments. The administrative data are derived from the administrative registers of the respective countries (e.g. the population register).

Sample Description and Size The sample comprised 7328 adults aged 16-74 years in Denmark, 7632 adults aged 16-74 years in Estonia, 5464 adults aged 16-74 years in Finland, 5128 adults aged 16-74 years in Norway, and 4469 adults aged 1674 years in Sweden (Fridberg et al. 2015).

Format and Access The Nordic PIAAC database is stored in safe domains of the Nordic National Statistical Institutions (Nordic NSIs). It is currently provided only for research purposes within the Network countries and can be accessed via NordMAN (Nordic Microdata Access Network) ${ }^{76}$. NordMAN describes the processes for obtaining access to Nordic PIAAC data combined with register data (application forms and procedures, confidentiality review and agreements, etc.). The data can be accessed via remote access systems at the statistical offices in Sweden, Finland, and Denmark.

There is not one standard dataset. Rather, datasets with register variables have to be created for specific research projects. When researchers apply for access, a dataset with the specific variables ordered is created for the research project in question. The application must be submitted to a committee comprising representatives from each country. In Sweden, for instance, the application must be approved by Statistics Sweden. If the application is approved, the researcher signs the necessary contracts and confidentiality agreements and is then allowed to analyse the Nordic microdata in SPSS, Stata, SAS, or R format via NordMAN. Prior to data delivery, all outputs are subject to output control by the data-hosting NSI. Fees are charged for the data preparation procedure and the use of the system.

Documentation Information on the methodology, design, and implementation of PIAAC can be found in the technical reports on the study (OECD 2014, 2016a; see also Chap. 2 in this volume) and in the results reports (Fridberg et al. 2015; OECD 2013, 2016b, c). A Danish-language, Estonian-language (and Russianlanguage), Finnish-language, Norwegian-language (and English-language), and Swedish-language version of the background questionnaire are available for downloading at the OECD PIAAC Data and Tools webpage, as are an international codebook and a derived variables codebook.

\footnotetext{
${ }^{76} \mathrm{http}: / /$ nordman.network/
} 


\subsection{PIAAC Longitudinal Data Files}

Four countries that participated in the first cycle of PIAAC (2011-2012)—Canada, Germany, Italy, and Poland-have carried out follow-up studies with different strategies and focus. Thereby, only the German PIAAC Longitudinal study included a reassessment of basic skills using PIAAC instruments (see Rammstedt et al. 2017a, b).

In Canada, a subset of the respondents of the Canadian social survey Longitudinal and International Study of Adults (LISA; $N=27,285)$ participated in PIAAC. These respondents are being reinterviewed biennially as part of LISA (see Situ 2015). The LISA study is described in more detail in Sect. 4.6 on linking PIAAC data to administrative data.

In Germany, respondents who had participated in the 2011/2012 PIAAC survey were reapproached for the panel study PIAAC-Longitudinal (PIAAC-L). PIAAC$\mathrm{L}(N=3758)$ consisted of three follow-up waves to the initial PIAAC 2012 survey, which were conducted in 2014, 2015, and 2016. Extensive background information and information on non-cognitive skills, household composition, and living conditions was collected, and a reassessment of literacy and numeracy was carried out in 2015.

A follow-up to PIAAC in Italy (2014/2015) collected longitudinal information on Italian PIAAC respondents $(N=2003)$ and focused on non-cognitive skills. A Polish follow-up to PIAAC (postPIAAC) also focused on non-cognitive skills. Conducted in 2014/2015 ( $N=5224)$, it collected additional background information on the PIAAC respondents as well as information on their non-cognitive skills (e.g. the Big Five personality traits, grit). Basic cognitive skills tests (e.g. working memory test or coding speed test) and a basic ICT skills test were applied (e.g. Palczyńska and Świst 2016). As the data from the Italian ${ }^{77}$ and Polish (to access the data, contact the Polish Educational Research Institute [IBE] $)^{78}$ follow-up studies have not yet been published and made available to external researchers, they are not presented in detail here. As only the German PIAAC-L study included a reassessment of basic skills, it will therefore be described in the following section.

\subsubsection{Germany}

\subsubsection{PIAAC-Longitudinal Scientific Use File}

File Description The German PIAAC-Longitudinal (PIAAC-L) study was a collaborative effort undertaken by GESIS - Leibniz Institute for the Social Sciences

\footnotetext{
${ }^{77}$ Istituto Nazionale per l'Analisi delle Politiche Pubbliche (INAPP); current email address: serviziost[at]istico[dot]inapp[dot]org.

${ }^{78}$ Current email: ibe[at]ibe[dot]edu[dot]pl.
} 


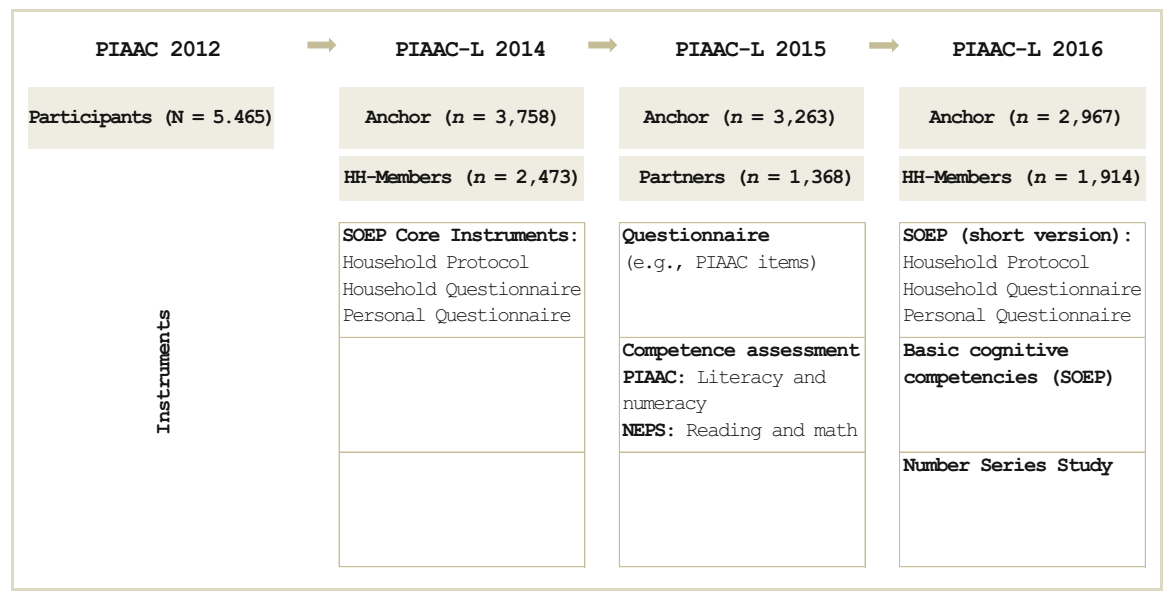

Note: SOEP=German Socio-Economic Panel; HH-Members = Additional household members

Fig. 4.1 German PIAAC-Longitudinal (PIAAC-L) study

(lead), the German Institute for Economic Research (DIW), and the Leibniz Institute for Educational Trajectories (LIfBi). PIAAC-L was designed as a threewave follow-up survey to PIAAC (2012), with data collections in 2014, 2015, and 2016 (for a overview see Fig. 4.1). The PIAAC-L questionnaires were based on core instruments from the German Socio-Economic Panel (SOEP) and also included various additional questions and modules on the respondents' background. In addition, assessment instruments from PIAAC and the National Educational Panel Study (NEPS) measuring key competencies were implemented.

The person questionnaire included questions on the following topics: background information, family, and childhood; biographical calendar; formal education (general and vocational education) and continuing professional education; work status, situation, and history; income and benefits; health, attitudes, personality, opinions, and satisfaction; and time use and leisure activities. The household questionnaire assessed living situation, conditions, and costs; household income and benefits and wealth; and children and other household members.

The objective of the PIAAC-L project was to significantly expand the German PIAAC database by adding a longitudinal dimension and enhancing the depth and breadth of information available on the German PIAAC respondents (for an overview of the rationale and design of the study, see Rammstedt et al. 2017a, b).

Mode of Data Collection Face-to-face interview (CAPI) and computer-based or paper-based cognitive assessment.

Sample Description and Size The sample comprised German PIAAC 2012 respondents aged 18-65 years who agreed to participate in PIAAC-L and other members of their household aged 18 years and over (total initial sample at the first wave: $N=6231$ ). Whereas the focus and the groups of addressed persons varied somewhat 
across waves, German PIAAC 2012 respondents $(N=5465)$ - the so-called anchor persons-were consistently the central response units in PIAAC-L (Zabal et al. 2016). Wave 1 was designed to target anchor persons $(n=3758)$ and their household members aged 18 years and over (i.e. born in 1996 or earlier; $n=2473$ ). In Wave 2 , anchor persons $(n=3263)$ and their partners, if living in the same household, were addressed $(n=1368)$. The design of the third wave was similar to that of the first wave: anchor persons $(n=2967)$ and all household members aged 18 years and over (i.e. born in 1998 or earlier) were to be interviewed $(n=1914)$.

Format and Access The German PIAAC-L data (GESIS et al. 2017) are available as a scientific use file (SPSS and Stata format) for academic research only, after signing a data distribution contract (in English or German). ${ }^{79}$ In addition, key information about the project (e.g. title, description, and duration) and the user must be provided. The data can be used only during the time period specified by the contract. Users are charged a processing fee and are expected to make publications resulting from the research available to the data provider. The data of the anchor persons from all three PIAAC-L waves can be matched to data from the German PIAAC Scientific Use File (see Sect. 4.4.3).

Documentation Information on the methodology, design, and implementation of PIAAC-L can be found in the German-language fieldwork report (Steinacker and Wolfert 2017) and the English-language technical reports on the study (Bartsch et al. 2017; Martin et al. 2018; Zabal et al. 2016). The person and household questionnaires (in German, as administered in the field, but with English labels) can be downloaded at the PIAAC Research Data Center website ${ }^{80}$ English-language codebooks for data on persons, households, and weights are available (in Excel and PDF format) on the respective websites.

\subsection{Linking PIAAC Data to Other Surveys}

Three PIAAC participating countries-Denmark, Singapore, and the United States-have surveyed persons who had been surveyed before in another largescale assessment, namely, the Programme for International Student Assessment (PISA).

In Denmark 1881 participants aged 15-16 years at PISA 2000 were retested and interviewed again in PIAAC 2011-2012. The Danish Center for Social Science Research (VIVE) is responsible for PIAAC; for more information on the corresponding data and the availability for the scientific research, please contact

\footnotetext{
${ }^{79}$ Available at https://www.gesis.org/en/piaac/rdc/data/piaac-longitudinal

${ }^{80} \mathrm{https} / / /$ www.gesis.org/en/piaac/rdc/data/piaac-longitudinal/
} 
VIVE. ${ }^{81}$ As no updated information on this dataset is currently available, it cannot be described in this volume.

Singapore surveyed persons who participated in PISA 2009. However, these data are not available for research purposes (OECD 2016a). Finally, in the United States, PISA 2012 participants were issued with PIAAC questionnaires. These datasets can be used for research purposes and will be described below.

\subsubsection{US Program for International Student Assessment Young Adult Follow-Up Study (PISA YAFS) Data}

File Description The Program for International Student Assessment Young Adult Follow-Up Study (PISA YAFS) is a new study that examines a key transition period for US young adults in terms of their characteristics, academic skills, and other life outcomes. It was conducted in the United States with a sample of students who participated in PISA 2012, when they were 15 years old. These students were assessed again 4 years later in 2016, at about age 19, with the OECD's Education and Skills Online (ESO) literacy, numeracy, and problem solving in technology-rich environments assessments, which were based on the Programme for the International Assessment of Adult Competencies (PIAAC). They were also given a background questionnaire about their education and employment status, attitudes, and interests.

Thus, in addition to providing information on skills performance at age 19, PISA YAFS can also examine the relationship between that performance and young adults' performance on PISA 2012 at age 15. Moreover, it can examine the relationship between their earlier PISA 2012 performance and other aspects of their lives at age 19, such as their engagement in postsecondary education, their participation in the workforce, their attitudes towards their lives, their ability to make their own choices, and their vocational interests.

Mode of Data Collection Online data collection, using a platform developed for PISA YAFS in combination with the OECD-provided platform Education and Skills Online (ESO). The specially developed PISA YAFS platform gathered information on (i) current education study status (participation, level of degree, area of study); (ii) formal education activities; and (iii) nonformal learning activities in the 12 months preceding the study. The ESO non-cognitive modules collected information on respondents' (i) basic demographics, (ii) career interests and intentionality (CII), (iii) behavioural performance competencies (BPC), and (iv) subjective wellbeing and health (SWBH). The ESO platform also assessed participants' skills in literacy, numeracy, and problem solving in technology-rich environments.

\footnotetext{
${ }^{81}$ https://www.vive.dk/da/velkommen/
} 
Sample Description and Size The PISA YAFS sample comprised around 2320 young adults who were about 19 years old in 2016, who participated in PISA 2012 at the age of 15 , and who provided contact information for follow-up.

Format and Access The PISA YAFS data are scheduled to be available in 2020. The data will be in the form of the public use files, provided in SPSS and SAS formats on the National Center for Education Statistics website. ${ }^{82}$

Documentation Information on the methodology, design, and implementation of PISA YAFS are planned to be available in 2020 and will be found in the technical and in the results reports on the study (https://nces.ed.gov/surveys/pisa/followup. asp). General information on the methodology, design, and implementation of PIAAC can be found in the technical reports on the study (OECD 2014, 2016a; see also Chap. 2 in this volume) and in the results reports (OECD 2013, 2016b, c). Information, questionnaires, and codebooks on PISA are available on the OECD website. $^{83}$

\subsection{PIAAC Data Files on Non-Cognitive Skills}

The PIAAC Pilot Studies on Non-Cognitive Skills were designed to test the measurement properties of nine personality scales: the Big Five, Traditionalism, Self-Control, Self-Efficacy, Honesty/Integrity, Socio-Emotional Skills, Intellectual Curiosity, Job Orientation Preferences, and Vocational Interests (Kankaraš 2017). The first study - the English Pilot Study on Non-Cognitive Skills-was realised with a complex design in the United States and the United Kingdom. The second study - the International Pilot Study on Non-Cognitive Skills-was realised in five countries (Germany, Spain, France, Japan, and Poland); the questionnaire focused on the properties of selected personality scales.

\subsubsection{PIAAC English Pilot Study on Non-Cognitive Skills $(S U F)$}

File Description This online survey (see also Kankaraš 2017) was designed to test the measurement properties of nine personality scales: the Big Five, Traditionalism, Self-Control, Self-Efficacy, Honesty/Integrity, Socio-Emotional Skills, Intellectual Curiosity, Job Orientation Preferences, and Vocational Interests. Eight of these nine scales were existing scales (or combinations of existing scales) available for use in the public domain. The study (data collection period: June-July 2016)

\footnotetext{
${ }^{82} \mathrm{https}: / /$ nces.ed.gov/surveys/pisa/followup.asp

${ }^{83} \mathrm{http}: / /$ www.oecd.org/pisa/data/database-pisa2000.htm
} 
was conducted in two phases, each with a somewhat different study design. The objectives of the online survey were to test (a) the measurement characteristics of the selected scales; (b) the relationships of the selected scales with background and other characteristics of respondents; (c) different item formulations-original vs. simplified; (d) different response options - with or without a neutral/middle category; (e) scales with different item formats-multiple choice vs. forced choice (Vocational Interests Scale); and (f) the new balanced scales (compared to the original unbalanced scales).

Mode of Data Collection The entire survey was conducted online. It was implemented using the SurveyMonkey platform.

Sample Description and Size The sample comprised 5910 adults aged 16-65 years from the United States and the United Kingdom in the first phase and 1606 in the second phase (only United States).

Format and Access The English Pilot Study on Non-Cognitive Skills (OECD 2018a) is available as a scientific use file (in SPSS and Stata format) for academic research only, after signing a data distribution contract. ${ }^{84}$ The scientific use file contains data from the first and second phases. In addition, key information about the project (e.g. title, description, and duration) and the user(s) must be provided. The data can be used only during the time period specified by the contract. Users are charged a processing fee.

Documentation Information on the methodology, design, and implementation of the PIAAC English Pilot Study on Non-Cognitive Skills can be found on the PIAAC Research Data Center website ${ }^{85}$ and the GESIS Data Archive. ${ }^{86}$ A questionnaire item bank (Excel format), a codebook (Excel format), and further information are also available on the aforementioned webpage.

\subsubsection{International Pilot Study on Non-Cognitive Skills (SUF)}

File Description This study was designed with the following objectives: first, to test the measurement characteristics of selected scales, and second, to test the cross-national comparability of selected scales. The measurement properties of nine personality scales - the Big Five, Traditionalism, Self-Control, Self-Efficacy, Honesty/Integrity, Socio-Emotional Skills, Intellectual Curiosity, Job Orientation Preferences, and Vocational Interests-were tested (data collection period: JanuaryMarch 2017).

\footnotetext{
${ }^{84}$ Available at https://www.gesis.org/en/piaac/rdc/data/piaac-pilot-studies-on-non-cognitive-skills

${ }^{85} \mathrm{https} / / /$ www.gesis.org/en/piaac/rdc/data/piaac-pilot-studies-on-non-cognitive-skills/

${ }^{86} \mathrm{https}: / /$ search.gesis.org/research_data/ZA6940
} 
Mode of Data Collection The entire survey was conducted online. It was implemented using the SurveyMonkey platform.

Sample Description and Size The sample comprised 6924 adults aged 16-65 years from Germany, Spain, France, Japan, and Poland.

Format and Access The International Pilot Study on Non-Cognitive Skills (OECD 2018 b) is available as a scientific use file (in SPSS and Stata format) for academic research only, after signing a data distribution contract. ${ }^{87}$ In addition, key information about the project (e.g. title, description, and duration) and the user(s) must be provided. The data can be used only during the time period specified by the contract. Users are charged a processing fee.

Documentation Information on the methodology, design, and implementation of the PIAAC International Pilot Study on Non-Cognitive Skills can be found on the PIAAC Research Data Center website ${ }^{88}$ and at the GESIS Data Archive. ${ }^{89}$ The questionnaires in the respective country languages (PDF format), item translations in the respective country languages (Excel format), an English-language codebook (Excel format), and further information are also available on the aforementioned webpage.

\section{References}

Bartsch, S., Poschmann, K., \& Burkhardt, L. (2017). Weighting in PIAAC-L 2014 (GESIS Papers No. 2017|06). Cologne: GESIS - Leibniz-Institute for the Social Sciences. http:// www.ssoar.info/ssoar/handle/document/50569. Accessed 12 December 2017.

Fridberg, T., Rosdahl, A., Halapuu, V., Valk, A., Malin, A., Hämäläinen, R., Andressen, A., Bjoerkeng, B., Stoerset, H., Soennesyn, J., Larsoson, A.-C., Lind, P., \& Mellander, E. (2015). Adult skills in the Nordic region. Key information-processing skills among adults in the Nordic region. Denmark: Nordic Council of Ministers. https://doi.org/10.6027/TN2015-535.

Friebe, J., Schmidt-Hertha, B., \& Tippelt, R. (Eds.). (2014). Kompetenzen im höheren Lebensalter. Ergebnisse der Studie "Competencies in Later Life" (CiLL). Bielefeld: Bertelsmann.

Friebe, J., Gebrande, J., Gnahs, D., Knauber, C., Schmidt-Hertha, B., Setzer, B., Tippelt, R., \& Weiß, C. (2017). Competencies in Later Life (CiLL) - Programme for the International Assessment of Adult Competencies (PIAAC), Germany ((Data file version 1.1.0) [ZA5969]). Cologne: GESIS Data Archive. https://doi.org/10.4232/1.12814.

GESIS - Leibniz Institute for the Social Sciences, German Socio-Economic Panel (SOEP) at DIW Berlin, LIfBi - Leibniz Institute for Educational Trajectories. (2017). PIAAC-Longitudinal (PIAAC-L), Germany ((Data file version 3.0.0) [ZA5989]). Cologne: GESIS Data Archive. https://doi.org/10.4232/1.12925.

Goodman, M., Finnegan, R., Mohadjer, L., Krenzke, T., \& Hogan, J. (2013). Literacy, numeracy, and problem solving in technology-rich environments among U.S. adults: Results from the Program for the International Assessment of Adult Competencies 2012: First look (NCES

\footnotetext{
${ }^{87}$ Available at https://www.gesis.org/en/piaac/rdc/data/piaac-pilot-studies-on-non-cognitive-skills ${ }^{88} \mathrm{https} / / /$ www.gesis.org/en/piaac/rdc/data/piaac-pilot-studies-on-non-cognitive-skills/

${ }^{89} \mathrm{https}: / /$ search.gesis.org/research_data/ZA6941
} 
2014-008) (U.S. Department of Education). Washington, DC: National Center for Education Statistics. http://nces.ed.gov/pubsearch. Accessed 19 July 2019.

Gravem, D. F., \& Lagerstrøm, B. O. (2013). Den internasjonale unders $\phi$ kelsen om lese- og tallforståelse - PIAAC (Dokumentasjonsrapport). Oslo: Statistics Norway. https://www.ssb.no/ utdanning/artikler-og-publikasjoner/_attachment/148094?_ts=142477b72f0. Accessed 19 July 2019.

Hogan, J., Montalvan, P., Diaz-Hoffmann, L., Dohrmann, S., Krenzke, T., Lemay, M., Mohadjer, L., \& Thornton, N. (2013). Program for the International Assessment of Adult Competencies 2012: U.S. Main Study Technical Report (NCES2014-047) (U.S. Department of Education). Washington, DC: National Center for Education Statistics. http://nces.ed.gov/pubsearch. Accessed 19 July 2019.

Hogan, J., Thornton, N., Diaz-Hoffmann, L., Mohadjer, L., Krenzke, T., Li, J., Van De Kerckhove, W., Yamamoto, K., \& Khorramdel, L. (2016a). U.S. Program for the International Assessment of Adult Competencies (PIAAC) 2012/2014: Main Study and National Supplement Technical Report (NCES2016-036REV) (U.S. Department of Education). Washington, DC: National Center for Education Statistics. http://nces.ed.gov/pubsearch. Accessed 19 July 2019.

Hogan, J., Thornton, N., Diaz-Hoffmann, L., Mohadjer, L., Krenzke, T., Li, J., \& Van De Kerckhove, W. (2016b). Program for the International Assessment of Adult Competencies (PIAAC) 2014: U.S. National Supplement Public Use Data Files-Prison (NCES 2016337REV). Washington, DC: National Center for Education Statistics. https://nces.ed.gov/pubsearch/ pubsinfo.asp?pubid=2016337REV. Accessed 19 July 2019.

Holtzman, S., Barone, J., Li, L., Krenzke, T., Hogan, J., Mohadjer, L., Carstens, R., \& Daniel, T. (2014a). Program for the International Assessment of Adult Competencies (PIAAC) 2012 U.S. Public Use File (NCES 2014045REV). Washington, DC: National Center for Education Statistics. https://nces.ed.gov/pubsearch/pubsinfo.asp?pubid=2014045REV. Accessed 19 July 2019.

Holtzman, S., Barone, J., Li, L., Krenzke, T., Hogan, J., Mohadjer, L., Carstens, R., \& Daniel, T. (2014b). Program for the International Assessment of Adult Competencies (PIAAC) 2012 U.S. Restricted Use File (NCES 2014046REV). Washington, DC: National Center for Education Statistics.

Holtzman, S., Kandathil, M., Kapur, L., Kline, D., Barone, J., Li, L., Krenzke, T., Hogan, J., Mohadjer, L., Carstens, R., Koehler, H., \& Daniel, T. (2016a). Program for the International Assessment of Adult Competencies (PIAAC) 2012/2014: U.S. National Supplement Public Use Data Files-Household (NCES 2016667REV). Washington, DC: National Center for Education Statistics.

Holtzman, S., Kandathil, M., Kapur, L., Kline, D., Barone, J., Li, L., Krenzke, T., Hogan, J., Mohadjer, L., Carstens, R., Koehler, H., \& Daniel, T. (2016b). Program for the International Assessment of Adult Competencies (PIAAC) 2012/2014: U.S. National Supplement Restricted Use Data Files-Household (NCES 2016668REV). Washington, DC: National Center for Education Statistics.

Istituto Nazionale per l'Analisi delle Politiche Pubbliche (INAPP). (2018). Program for the International Assessment of Adult Competencies (PIAAC) 2012 Italy. Rome: Istituto Nazionale per l'Analisi delle Politiche Pubbliche.

Kankaraš, M. (2017). Personality matters (OECD Education Working Papers No. 157). Paris: OECD Publishing.

Maehler, D. B., Jakowatz, S., \& Konradt, I. (2020). PIAAC Bibliographie - 2008-2019 (GESIS Papers, Nr. 04/2020). Cologne: GESIS - Leibniz Institute for the Social Sciences. https:// doi.org/10.21241/ssoar.67732.

Martin, S., Zabal, A., \& Rammstedt, B. (2018). PIAAC-L data collection 2016: Technical report (GESIS Papers No. 2018|05). Cologne: GESIS - Leibniz-Institute for the Social Sciences. https://nbn-resolving.org/urn:nbn:de:0168. Accessed 5 May 2019.

Michaelidou-Evripidou, A., Modestou, M., Karagiorgi, Y., Polydorou, A., Nicolaidou, M., Afantiti-Lamprianou, T., Kendeou, P., Tsouris, C., \& Loukaides, C. (2016). Programme for 
the International Assessment of Adult Competencies (PIAAC), Cyprus (Data file version 1.1.0 [ZA5650]). Cologne: GESIS Data Archive. https://doi.org/10.4232/1.12632.

Ministry of Education of New Zealand. (2016). Programme for the International Assessment of Adult Competencies (PIAAC), New Zealand Public Use File - Extended. Wellington: Ministry of Education.

Organisation for Economic Co-operation and Development (OECD). (2013). OECD skills outlook 2013: First results from the survey of adult skills. Paris: OECD Publishing. https://doi.org/10.1787/9789264204256-en.

Organisation for Economic Co-operation and Development (OECD). (2014). Technical report of the Survey of Adult Skills (PIAAC). Paris: OECD. http://www.oecd.org/skills/piaac/ _Technical\%20Report_17OCT13.pdf. Accessed 5 May, 2019.

Organisation for Economic Co-operation and Development (OECD). (2016a). Survey of adult skills technical report (2nd ed.). Paris: OECD. http://www.oecd.org/skills/piaac/ PIAAC_Technical_Report_2nd_Edition_Full_Report.pdf. Accessed 5 May 2019.

Organisation for Economic Co-operation and Development (OECD). (2016b). Skills matter: Further results from the survey of adult skills. Paris: OECD Publishing. https://doi.org/10.1787/9789264258051-en.

Organisation for Economic Co-operation and Development (OECD). (2016c). The survey of adult skills - Reader's companion (2nd ed.). Paris: OECD Publishing. https://doi.org/10.1787/9789264258075-en.

Organisation for Economic Co-operation and Development (OECD). (2016d). Programme for the International Assessment of Adult Competencies (PIAAC), Austria Public Use File (Version: 17343010, prgautp1.sav). Paris: OECD Publishing. https://'webfs.oecd.org/piaac/puf-data/. Accessed 5 May 2019.

Organisation for Economic Co-operation and Development (OECD). (2016e). Programme for the International Assessment of Adult Competencies (PIAAC), Belgium Public Use File (Version: 18224205, prgbelp1.sav). Paris: OECD Publishing. https://webfs.oecd.org/piaac/puf-data/. Accessed 5 May 2019.

Organisation for Economic Co-operation and Development (OECD). (2016f). Programme for the International Assessment of Adult Competencies (PIAAC), Canada Public Use File (Version: 88830378, prgcanp1.sav). Paris: OECD Publishing. https://webfs.oecd.org/piaac/puf-data/. Accessed 5 May 2019.

Organisation for Economic Co-operation and Development (OECD). (2016g). Programme for the International Assessment of Adult Competencies (PIAAC), Chile Public Use File (Version: 17135698, prgchlp1.sav). Paris: OECD Publishing. https://webfs.oecd.org/piaac/puf-data/. Accessed 5 May 2019.

Organisation for Economic Co-operation and Development (OECD). (2016h). Programme for the International Assessment of Adult Competencies (PIAAC), Czech Republic Public Use File (Version: 20736629, prgczep1.sav). Paris: OECD Publishing. https://webfs.oecd.org/piaac/ puf-data/. Accessed 5 May 2019.

Organisation for Economic Co-operation and Development (OECD). (2016i). Programme for the International Assessment of Adult Competencies (PIAAC), Denmark Public Use File (Version: 24972525, prgdnkp1.sav). Paris: OECD Publishing. https://webfs.oecd.org/piaac/puf-data/. Accessed 5 May 2019.

Organisation for Economic Co-operation and Development (OECD). (2016j). Programme for the International Assessment of Adult Competencies (PIAAC), Estonia Public Use File (Version: 25276973, prgestp1.sav). Paris: OECD Publishing. https://webfs.oecd.org/piaac/puf-data/. Accessed 5 May 2019.

Organisation for Economic Co-operation and Development (OECD). (2016k). Programme for the International Assessment of Adult Competencies (PIAAC), France Public Use File (Version: 23516989, prgfrap1.sav). Paris: OECD Publishing. https://webfs.oecd.org/piaac/puf-data/. Accessed 5 May 2019.

Organisation for Economic Co-operation and Development (OECD). (20161). Programme for the International Assessment of Adult Competencies (PIAAC), Finland Public Use File (Version: 
18842845, prgfinp1.sav). Paris: OECD Publishing. https://webfs.oecd.org/piaac/puf-data/. Accessed 5 May 2019.

Organisation for Economic Co-operation and Development (OECD). (2016m). Programme for the International Assessment of Adult Competencies (PIAAC), Germany Public Use File (Version: 30110173, prggbrp1.sav). Paris: OECD Publishing. https://webfs.oecd.org/piaac/puf-data/. Accessed 5 May, 2019.

Organisation for Economic Co-operation and Development (OECD). (2016n). Programme for the International Assessment of Adult Competencies (PIAAC), Greece Public Use File (Version: 15965250, prggrcp1.sav). Paris: OECD Publishing. https://webfs.oecd.org/piaac/puf-data/. Accessed 5 May 2019.

Organisation for Economic Co-operation and Development (OECD). (2016o). Programme for the International Assessment of Adult Competencies (PIAAC), Ireland Public Use File (Version: 19982813, prgirlp1.sav). Paris: OECD Publishing. https://webfs.oecd.org/piaac/puf-data/. Accessed 5 May 2019.

Organisation for Economic Co-operation and Development (OECD). (2016p). Programme for the International Assessment of Adult Competencies (PIAAC), Israel Public Use File (Version: 18069090, prgisrp1.sav). Paris: OECD Publishing. https://webfs.oecd.org/piaac/puf-data/. Accessed 5 May 2019.

Organisation for Economic Co-operation and Development (OECD). (2016q). Programme for the International Assessment of Adult Competencies (PIAAC), Italy Public Use File (Version: 15433181, prgitap1.sav). Paris: OECD Publishing. https://webfs.oecd.org/piaac/puf-data/. Accessed 5 May 2019.

Organisation for Economic Co-operation and Development (OECD). (2016r). Programme for the International Assessment of Adult Competencies (PIAAC), Japan Public Use File (Version: 17505957, prgjpnp1.sav). Paris: OECD Publishing. https://webfs.oecd.org/piaac/puf-data/. Accessed 5 May 2019.

Organisation for Economic Co-operation and Development (OECD). (2016s). Programme for the International Assessment of Adult Competencies (PIAAC), Korea Public Use File (Version: 22217045, prgkorp1.sav). Paris: OECD Publishing. https://webfs.oecd.org/piaac/puf-data/. Accessed 5 May 2019.

Organisation for Economic Co-operation and Development (OECD). (2016t). Programme for the International Assessment of Adult Competencies (PIAAC), Lithuania Public Use File (Version: 17305986, prgltup1.sav). Paris: OECD Publishing. https://webfs.oecd.org/piaac/puf-data/. Accessed 5 May 2019.

Organisation for Economic Co-operation and Development (OECD). (2016u). Programme for the International Assessment of Adult Competencies (PIAAC), Netherlands Public Use File (Version: 18028845, prgnldp1.sav). Paris: OECD Publishing. https://webfs.oecd.org/piaac/pufdata/. Accessed 5 May 2019.

Organisation for Economic Co-operation and Development (OECD). (2016v). Programme for the International Assessment of Adult Competencies (PIAAC), Norway Public Use File (Version: 17723269, prgnorp1.sav). Paris: OECD Publishing. https://webfs.oecd.org/piaac/puf-data/. Accessed 5 May 2019.

Organisation for Economic Co-operation and Development (OECD). (2016w). Programme for the International Assessment of Adult Competencies (PIAAC), New Zealand Public Use File (Version: 21235362, prgnzlp1.sav). Paris: OECD Publishing. https://webfs.oecd.org/piaac/pufdata/. Accessed 5 May, 2019.

Organisation for Economic Co-operation and Development (OECD). (2016x). Programme for the International Assessment of Adult Competencies (PIAAC), Poland Public Use File (Version: 30634733, prgpolp1.sav). Paris: OECD Publishing. https://webfs.oecd.org/piaac/puf-data/. Accessed 5 May 2019.

Organisation for Economic Co-operation and Development (OECD). (2016y). Programme for the International Assessment of Adult Competencies (PIAAC), Russian Federation Public Use File (Version: 13378965, prgrusp1.sav). Paris: OECD Publishing. https://webfs.oecd.org/piaac/pufdata/. Accessed 5 May 2019. 
Organisation for Economic Co-operation and Development (OECD). (2016z). Programme for the International Assessment of Adult Competencies (PIAAC), Singapore Public Use File (Version: 18353722, prgsgpp1.sav). Paris: OECD Publishing. https://webfs.oecd.org/piaac/ puf-data/. Accessed 5 May 2019.

Organisation for Economic Co-operation and Development (OECD). (2016aa). Programme for the International Assessment of Adult Competencies (PIAAC), Slovak Republic Public Use File (Version: 18921861, prgsvkp1.sav). Paris: OECD Publishing. https://webfs.oecd.org/piaac/ puf-data/. Accessed 5 May, 2019.

Organisation for Economic Co-operation and Development (OECD). (2016bb). Programme for the International Assessment of Adult Competencies (PIAAC), Slovenia Public Use File (Version: 18125930, prgsvnp1.sav). Paris: OECD Publishing. https://webfs.oecd.org/piaac/ puf-data/. Accessed 5 May 2019.

Organisation for Economic Co-operation and Development (OECD). (2016cc). Programme for the International Assessment of Adult Competencies (PIAAC), Spain Public Use File (Version: 20201797, prgespp1.sav). Paris: OECD Publishing. https://webfs.oecd.org/piaac/puf-data/. Accessed 5 May, 2019.

Organisation for Economic Co-operation and Development (OECD). (2016dd). Programme for the International Assessment of Adult Competencies (PIAAC), Sweden Public Use File (Version: 15716978, prgswep1.sav). Paris: OECD Publishing. https://webfs.oecd.org/piaac/ puf-data/. Accessed 5 May 2019.

Organisation for Economic Co-operation and Development (OECD). (2016ee). Programme for the International Assessment of Adult Competencies (PIAAC), Turkey Public Use File (Version: 16765802, prgturp1.sav). Paris: OECD Publishing. https://webfs.oecd.org/piaac/puf-data/. Accessed 5 May 2019.

Organisation for Economic Co-operation and Development (OECD). (2016ff). Programme for the International Assessment of Adult Competencies (PIAAC), United Kingdom Public Use File (Version: 17016050, prgusap1.sav). Paris: OECD Publishing. https://webfs.oecd.org/piaac/ puf-data/. Accessed 5 May 2019.

Organisation for Economic Co-operation and Development (OECD). (2016gg). Programme for the International Assessment of Adult Competencies (PIAAC), United States Public Use File (Version: 17016050, prgusap1.sav). Paris: OECD Publishing. https://webfs.oecd.org/piaac/ puf-data/. Accessed 5 May 2019.

Organisation for Economic Co-operation and Development (OECD). (2017a). Programme for the International Assessment of Adult Competencies (PIAAC), Austria log file. Data file version 2.0.0 [ZA6712_AT.data.zip]. Cologne: GESIS Data Archive. https://doi.org/10.4232/1.12955

Organisation for Economic Co-operation and Development (OECD). (2017b). Programme for the International Assessment of Adult Competencies (PIAAC), Belgium log file. Data file version 2.0.0 [ZA6712_BE.data.zip]. Cologne: GESIS Data Archive. https://doi.org/10.4232/1.12955

Organisation for Economic Co-operation and Development (OECD). (2017c). Programme for the International Assessment of Adult Competencies (PIAAC), Germany log file. Data file version 2.0.0 [ZA6712_DE.data.zip]. Cologne: GESIS Data Archive. https://doi.org/10.4232/1.12955

Organisation for Economic Co-operation and Development (OECD). (2017d). Programme for the International Assessment of Adult Competencies (PIAAC), Denmark log file. Data file version 2.0.0 [ZA6712_DK.data.zip]. Cologne: GESIS Data Archive. https://doi.org/10.4232/1.12955

Organisation for Economic Co-operation and Development (OECD). (2017e). Programme for the International Assessment of Adult Competencies (PIAAC), Estonia log file. Data file version 2.0.0 [ZA6712_EE.data.zip]. Cologne: GESIS Data Archive. https://doi.org/10.4232/1.12955

Organisation for Economic Co-operation and Development (OECD). (2017f). Programme for the International Assessment of Adult Competencies (PIAAC), Spain log file. Data file version 2.0.0 [ZA6712_ES.data.zip]. Cologne: GESIS Data Archive. https://doi.org/10.4232/1.12955

Organisation for Economic Co-operation and Development (OECD). (2017g). Programme for the International Assessment of Adult Competencies (PIAAC), Finland log file. Data file version 2.0.0 [ZA6712_FI.data.zip]. Cologne: GESIS Data Archive. https://doi.org/10.4232/1.12955 
Organisation for Economic Co-operation and Development (OECD). (2017h). Programme for the International Assessment of Adult Competencies (PIAAC), France log file. Data file version 2.0.0 [ZA6712_FR.data.zip]. Cologne: GESIS Data Archive. https://doi.org/10.4232/1.12955

Organisation for Economic Co-operation and Development (OECD). (2017i). Programme for the International Assessment of Adult Competencies (PIAAC), United Kingdom $\log$ file. Data file version 2.0.0 [ZA6712_GB.data.zip]. Cologne: GESIS Data Archive. https://doi.org/10.4232/1.12955

Organisation for Economic Co-operation and Development (OECD). (2017j). Programme for the International Assessment of Adult Competencies (PIAAC), Ireland log file. Data file version 2.0.0 [ZA6712_IE.data.zip]. Cologne: GESIS Data Archive. https://doi.org/10.4232/1.12955

Organisation for Economic Co-operation and Development (OECD). (2017k). Programme for the International Assessment of Adult Competencies (PIAAC), Italy log file. Data file version 2.0.0 [ZA6712_IT.data.zip]. Cologne: GESIS Data Archive. https://doi.org/10.4232/1.12955

Organisation for Economic Co-operation and Development (OECD). (20171). Programme for the International Assessment of Adult Competencies (PIAAC), South Korea log file. Data file version 2.0.0 [ZA6712_KR.data.zip]. Cologne: GESIS Data Archive. https://doi.org/10.4232/1.12955

Organisation for Economic Co-operation and Development (OECD). (2017m). Programme for the International Assessment of Adult Competencies (PIAAC), Netherlands log file. Data file version 2.0.0 [ZA6712_NL.data.zip]. Cologne: GESIS Data Archive. https://doi.org/10.4232/1.12955

Organisation for Economic Co-operation and Development (OECD). (2017n). Programme for the International Assessment of Adult Competencies (PIAAC), Norway log file. Data file version 2.0.0 [ZA6712_NO.data.zip]. Cologne: GESIS Data Archive. https://doi.org/10.4232/1.12955

Organisation for Economic Co-operation and Development (OECD). (2017o). Programme for the International Assessment of Adult Competencies (PIAAC), Poland log file. Data file version 2.0.0 [ZA6712_PL.data.zip]. Cologne: GESIS Data Archive. https://doi.org/10.4232/1.12955

Organisation for Economic Co-operation and Development (OECD). (2017p). Programme for the International Assessment of Adult Competencies (PIAAC), Slovakia log file. Data file version 2.0.0 [ZA6712_SK.data.zip]. Cologne: GESIS Data Archive. https://doi.org/10.4232/1.12955

Organisation for Economic Co-operation and Development (OECD). (2017q). Programme for the International Assessment of Adult Competencies (PIAAC), United States log file. Data file version 2.0.0 [ZA6712_US.data.zip]. Cologne: GESIS Data Archive. https://doi.org/10.4232/1.12955

Organisation for Economic Co-operation and Development (OECD). (2018a). Programme for the International Assessment of Adult Competencies (PIAAC), English Pilot Study on Non-Cognitive Skills. Data file version 1.0.0 [ZA6940]. Cologne: GESIS Data Archive. https://doi.org/10.4232/1.13062

Organisation for Economic Co-operation and Development (OECD). (2018b). Programme for the International Assessment of Adult Competencies (PIAAC), international pilot study on non-cognitive skills (Data file version 1.0.0 [ZA6941]). Cologne: GESIS Data Archive. https://doi.org/10.4232/1.13063.

Organisation for Economic Co-operation and Development (OECD). (2019a). Beyond proficiency. Using log files to understand respondent behaviour in the survey of adult skills. Paris: OECD Publishing. https://doi.org/10.1787/23078731. Accessed 5 May 2019.

Organisation for Economic Co-operation and Development (OECD). (2019b). Programme for the International Assessment of Adult Competencies (PIAAC), Ecuador Public Use File (Version: 17688347, prgecup1.sav). Paris: OECD Publishing. https://webfs.oecd.org/piaac/puf-data/. Accessed 20 December 2019.

Organisation for Economic Co-operation and Development (OECD). (2019c). Programme for the International Assessment of Adult Competencies (PIAAC), Hungary Public Use File (Version: 20439451, prghunp1.sav). Paris: OECD Publishing. https://webfs.oecd.org/piaac/puf-data/. Accessed 20 December 2019. 
Organisation for Economic Co-operation and Development (OECD). (2019d). Programme for the International Assessment of Adult Competencies (PIAAC), Kazakhstan Public Use File (Version: 20450859, prgkazp1.sav). Paris: OECD Publishing. https://webfs.oecd.org/piaac/ puf-data/. Accessed 20 December 2019.

Organisation for Economic Co-operation and Development (OECD). (2019e). Programme for the International Assessment of Adult Competencies (PIAAC), Mexico Public Use File (Version: 19760643, prgmexp1.sav). Paris: OECD Publishing. https://webfs.oecd.org/piaac/puf-data/. Accessed 20 December 2019.

Organisation for Economic Co-operation and Development (OECD). (2019f). Programme for the International Assessment of Adult Competencies (PIAAC), Peru Public Use File (Version: 22883339, prgperp1.sav). Paris: OECD Publishing. https://webfs.oecd.org/piaac/puf-data/. Accessed 20 December 2019.

Organisation for Economic Co-operation and Development (OECD). (2019g). Programme for the International Assessment of Adult Competencies (PIAAC), United States Public Use File (Version: 19748455, prgusap1_2017.sav). Paris: OECD Publishing. https://webfs.oecd.org/ piaac/puf-data/. Accessed 20 December 2019.

Palczyńska, M., \& Świst, K. (2016). Measurement properties of non-cognitive scales in the Polish follow-up study on PIAAC (POSTPIAAC) (OECD Education Working Paper No. 149). Paris: OECD Publishing. https://doi.org/10.1787/19939019. Accessed 5 May 2019.

Perry, A., Helmschrott, S., Konradt, I., \& Maehler, D. B. (2017). User guide for the German PIAAC scientific use file (GESIS Papers No 2017|23). Cologne: GESIS - Leibniz-Institute for the Social Sciences. http://nbn-resolving.de/urn:nbn:de:0168-ssoar-54438-3. Accessed 10 May 2019.

Rammstedt, B., Ackermann, D., Helmschrott, S., Klaukien, A., Maehler, D., Martin, S., Massing, N., Zabal, A. (Eds). (2013). Grundlegende Kompetenzen Erwachsener im internationalen Vergleich: Ergebnissevon PIAAC 2012. Münster: Waxmann. https://nbn-resolving.org/ urn:nbn:de:0168-ssoar-360687

Rammstedt, B., Martin, S., Zabal, A., Konradt, I., Maehler, D., Perry, A., et al. (2016a). Programme for the International Assessment of Adult Competencies (PIAAC), Germany Reduced version ((Data file version 2.2.0) [ZA5845]). Cologne: GESIS Data Archive. https://doi.org/10.4232/1.12660.

Rammstedt, B., Martin, S., Zabal, A., Konradt, I., Maehler, D., Perry, A., et al. (2016b). Programme for the International Assessment of Adult Competencies (PIAAC), Germany Extended version - Regional data ((Data file version 1.0.0) [ZA5846]). Cologne: GESIS Data Archive. https://doi.org/10.4232/1.12560.

Rammstedt, B., Martin, S., Zabal, A., Helmschrott, S., Konradt, I., \& Maehler, D. (2017a). Programme for the International Assessment of Adult Competencies (PIAAC), Germany Extended version - microm data ((Data file version 1.0.0) [ZA5963]). Cologne: GESIS Data Archive. https://doi.org/10.4232/1.12926.

Rammstedt, B., Martin, S., Zabal, A., Carstensen, C., \& Schupp, J. (2017b). The PIAAC longitudinal study in Germany: Rationale and design. Large-scale Assessment in Education, 5(4). https://doi.org/10.1186/s40536-017-0040-.

Rampey, B. D., Finnegan, R., Goodman, M., Mohadjer, L., Krenzke, T., Hogan, J., \& Provasnik, S. (2016). Skills of U.S. unemployed, young, and older adults in sharper focus: Results from the Program for the International Assessment of Adult Competencies (PIAAC) 2012/2014: First look (NCES 2016-039rev) (U.S. Department of Education). Washington, DC: National Center for Education Statistics. http://nces.ed.gov/pubsearch. Accessed 19 July 2019.

Situ, J. (2015). Using the program for international assessment of adult competencies direct measures of skills in the longitudinal and international study of adults (Longitudinal and International Study of Adults Research Paper Series No. 89-648-X). Statistics Canada. https:/ /www150.statcan.gc.ca/n1/pub/89-648-x/89-648-x2015001-eng.htm. Accessed 5 May 2019.

Solga, H., \& Heisig, J. P. (2015). Programme for the International Assessment of Adult Competencies (PIAAC), Germany - Prime Age (2012) (Data file version 1.1.0 [ZA5951]). Cologne: GESIS Data Archive. https://doi.org/10.4232/1.12386. 
Statistics Austria. (2014). Programme for the International Assessment of Adult Competencies (PIAAC), Scientific Use File PIAAC 2011/12 for Austria. Vienna: Statistics Austria.

Statistics Austria. (2015). Programme for the International Assessment of Adult Competencies (PIAAC), public use file extended PIAAC 2011/12 for Austria. Vienna: Statistics Austria.

Statistics Canada. (2013). PUMF 2012 - Programme for the International Assessment of Adult Competencies (PIAAC) (Catalogue number. 89-555-X2013002). Ottawa: Statistics Canada.

Statistics Norway. (2015). Survey of adult skills (PIAAC) 2012 ([Dataset] (NSD2135)). Bergen: Norwegian Social Science Data Services. https://doi.org/10.18712/NSD-NSD2135-V1.

Steinacker, G., \& Wolfert, S. (2017). Durchführung der 2. Erhebungswelle von PIAAC-L (Kooperative längsschnittliche Weiterverfolgung der PIAAC-Studie in Deutschland): Feldbericht zur Erhebung 2015 (GESIS Papers No. 2017|04). Cologne: GESIS - Leibniz Institute for the Social Sciences. http://www.ssoar.info/ssoar/handle/document/50488. Accessed 12 December 2017.

Zabal, A., Martin, S., Massing, N., Ackermann, D., Helmschrott, S., Barkow, I., \& Rammstedt, B. (2014). PIAAC Germany 2012: Technical report. Münster: Waxmann.

Zabal, A., Martin, S., \& Rammstedt, B. (2016). PIAAC-L data collection 2014: Technical report. Follow-up to PIAAC Germany 2012 (GESIS Papers No. 2016|17). Cologne: GESIS Leibniz-Institute for the Social Sciences. http://www.ssoar.info/ssoar/handle/document/49665. Accessed 12 December 2017.

Open Access This chapter is licensed under the terms of the Creative Commons Attribution 4.0 International License (http://creativecommons.org/licenses/by/4.0/), which permits use, sharing, adaptation, distribution and reproduction in any medium or format, as long as you give appropriate credit to the original author(s) and the source, provide a link to the Creative Commons license and indicate if changes were made.

The images or other third party material in this chapter are included in the chapter's Creative Commons license, unless indicated otherwise in a credit line to the material. If material is not included in the chapter's Creative Commons license and your intended use is not permitted by statutory regulation or exceeds the permitted use, you will need to obtain permission directly from the copyright holder.

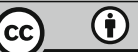

